\title{
Pituitary Adenylate Cyclase-Activating Polypeptide Excites Proopiomelanocortin Neurons: Implications for the Regulation of Energy Homeostasis
}

\author{
Rachel Chang ${ }^{\mathrm{a}}$ Jennifer Hernande $z^{\mathrm{b}}$ Cassandra Gastelum ${ }^{\mathrm{a}}$ \\ Kaitlyn Guadagno $^{\mathrm{b}} \quad$ Lynnea Perez $^{\mathrm{a}} \quad$ Edward J. Wagner ${ }^{\mathrm{a}, \mathrm{b}}$ \\ ${ }^{a}$ Graduate College of Biomedical Sciences, Western University of Health Sciences, Pomona, CA, USA; ${ }^{b}$ College of \\ Osteopathic Medicine of the Pacific, Western University of Health Sciences, Pomona, CA, USA
}

\author{
Keywords \\ PACAP · Proopiomelanocortin - Ventromedial nucleus . \\ Arcuate nucleus · TRPC channels · Metabolism . \\ Energy balance $\cdot$ Appetite $\cdot$ Sex differences
}

\begin{abstract}
Objective: We examined whether pituitary adenylate cyclase-activating polypeptide (PACAP) excites proopiomelanocortin (POMC) neurons via PAC1 receptor mediation and transient receptor potential cation (TRPC) channel activation. Methods: Electrophysiological recordings were done in slices from both intact male and ovariectomized (OVX) female PACAP-Cre mice and eGFP-POMC mice. Results: In recordings from POMC neurons in eGFP-POMC mice, PACAP induced a robust inward current and increase in conductance in voltage clamp, and a depolarization and increase in firing in current clamp. These postsynaptic actions were abolished by inhibitors of the PAC1 receptor, TRPC channels, phospholipase C, phosphatidylinositol-3-kinase, and protein kinase C. Estradiol augmented the PACAP-induced inward current, depolarization, and increased firing, which was abrogated by estrogen receptor (ER) antagonists. In optogenetic recordings from POMC neurons in PACAP-Cre mice, high-frequency photostimulation induced inward currents, depolarizations, and increased firing that were signifi-
\end{abstract}

cantly enhanced by $\mathrm{G}_{\mathrm{q}}$-coupled membrane $\mathrm{ER}$ signaling in an ER antagonist-sensitive manner. Importantly, the PACAPinduced excitation of POMC neurons was notably reduced in obese, high-fat (HFD)-fed males. In vivo experiments revealed that intra-arcuate nucleus (ARC) PACAP as well as chemogenetic and optogenetic stimulation of ventromedial nucleus (VMN) PACAP neurons produced a significant decrease in energy intake accompanied by an increase in energy expenditure, effects blunted by HFD in males and partially potentiated by estradiol in OVX females. Conclusions: These findings reveal that the PACAP-induced activation of PAC1 receptor and TRPC5 channels at VMN PACAP/ARC POMC synapses is potentiated by estradiol and attenuated under conditions of diet-induced obesity/insulin resistance. As such, they advance our understanding of how PACAP regulates the homeostatic energy balance circuitry under normal and pathophysiological circumstances.

(c) 2020 S. Karger AG, Basel

\section{Introduction}

Pituitary adenylate cyclase-activating polypeptide (PACAP) is a 38 -amino acid C-terminally alpha-amidated peptide that belongs to the vasoactive intestinal polypeptide (VIP)-secretin-growth hormone-releasing hor- karger@karger.com

(C) 2020 S. Karger AG, Basel

www.karger.com/nen

Karger
Edward J. Wagner

College of Osteopathic Medicine of the Pacific

Western University of Health Sciences, 309 E. 2nd Street

Pomona, CA 91766 (USA)

ewagner@westernu.edu 
mone-glucagon superfamily. PACAP is widely distributed in the brain and peripheral organs, such as endocrine pancreas, gonads, respiratory and urogenital tracts. PACAP exerts a large range of physiological effects including the control of neurotransmitter and hormone release, behavioral, neurotrophic, and neuroendocrine actions [1]. Two types of PACAP receptors have been characterized: type I receptors, named PACAP-specific receptor (PAC1R), exhibit a high affinity for PACAP and a much lower affinity for VIP, and two subtypes of type II receptors (VPAC1R and VPAC2R) that recognize both PACAP and VIP with high affinity [1]. PACAP and its receptors, especially PAC1R and VPAC2R, are expressed abundantly in the hypothalamus, and there is clear evidence that PACAP is involved in the control of multiple hypothalamic functions $[2,3]$. PAC1R, which binds PACAP with an approximately twofold higher affinity compared with the VPAC receptors, has a widespread distribution throughout the central nervous system, and is especially prominent in hypothalamic nuclei such as the dorsomedial nucleus, arcuate nucleus (ARC), and ventromedial nucleus (VMN) $[1,3]$.

VMN neurons, particularly those expressing steroidogenic factor (SF)-1 encoded by the NR5A1 gene, are critically involved in the regulation of energy balance and exert this function by projecting both locally within the hypothalamus, as well as to other extrahypothalamic sites [4-7]. SF-1-expressing neurons in the dorsomedial VMN have been shown to synapse directly with proopiomelanocortin (POMC) neurons in the ARC and to several autonomic centers, thus regulating sympathetic nervous system outflow $[6,8]$. Targeted deletion of the VMN SF-1 results in agenesis of the VMN and obesity, and microarray studies have identified several VMN-enriched genes whose expression is positively modulated by SF-1, including PACAP [9-11]. VMN PACAP signaling regulates energy homeostasis, as demonstrated by studies showing decreased PACAP mRNA expression in the VMN following a 48-h fast, and increased expression associated with long-term consumption (approximately 5 weeks) of highfat diet (HFD) $[3,11,12]$.

Among the pleiotropic roles of PACAP, studies have shown PACAP to regulate thermogenesis, energy expenditure, the mobilization of energy stores, and stress circuits. When PACAP is injected into the VMN, it increases body temperature and uncoupling protein (UCP) 1 expression and decreases interscapular brown adipose tissue and perirenal white adipose tissue reserves $[1,3,13]$. Studies have also supported a role for PACAP in regulating activity, as PACAP delivered by an injection directly into the VMH increased locomotor activity in murines $[3,13]$. Catabolic effects of PACAP increase the mobilization of energy stores via the sympathetic nervous system, in which activation of hypothalamic PACAP signaling have been shown to catabolize lipids in lieu of carbohydrate as their primary source of energy [1]. In addition, PACAP promotes sustained elevations in hypoglycemia-induced epinephrine secreted by the adrenal medulla, and intracerebroventricularly injected PACAP stimulates hepatic glucose production [1]. Likewise, chemogenetic activation of VMN PACAP neurons decreases insulin secretion and increases glucose levels in response to a glucose challenge [14].

PACAP exerts its biological action by binding to $\mathrm{G}$ protein-coupled membrane receptors [1]. As stated above, three receptors have been cloned, including cognate $\mathrm{PAC} 1$ receptor and two receptors with similar high affinity for PACAP and VIP; namely VPAC1 and VPAC2 receptors, and a considerable amount of PAC1 and VPAC2 expression is observed in the hypothalamus [2]. Studies found that the PACAP/PAC1 system potentiated growth factor-induced proliferation of mouse cortical neuronal progenitor cells at E14.5 via a $\mathrm{G}_{\mathrm{q}}$ - but not $\mathrm{G}_{\mathrm{s}^{-}}$ mediated phospholipase C (PLC)/inositol 1,4,5-trisphosphate (IP3)-dependent signaling pathway [15]. Coupled with the fact that PACAP activates transient receptor potential cation (TRPC) channels and inactivates A-type $\mathrm{K}+$ channels in rat carotid body primarily via stimulation of a PLC/protein kinase C pathway [16], this suggests that PACAP can bind to hypothalamic PAC1 receptors that are coupled to $G_{\mathrm{q}}$, inducing activation of PLC that results in IP3 and diacylglycerol formation, and subsequent IP3$\mathrm{R}$ and PKC activation. Previous studies have shown that TRPC5 mRNA is highly expressed in POMC neurons, and it appears that the insulin- and leptin-induced excitation of POMC neurons occurs via the opening of TRPC5 channels [17]. Insulin and leptin each bind to their cognate receptors to converge on an insulin receptor substrate/phosphatidylinositol 3-kinase (PI3K)/PLC $\gamma$ signaling pathway resulting in TRPC5 channel activation, and phosphorylation of IRS proteins activates PI3K that subsequently activates PLC $\gamma 1$ to augment TRPC channel activity and POMC neuronal excitability [17]. This pathway may very well represent the manner in which PAC1 receptor activation excites $\mathrm{POMC}$ neurons to produce its anorexigenic effects.

Recent studies also indicate that estrogenic regulation of the PACAPergic system may be important in potentiating the ability of PACAP to regulate the response to
Chang/Hernandez/Gastelum/Guadagno/ Perez/Wagner 
stress. Chronic stress upregulates PAC1R expression within brain regions known to subserve stress and fear processes, including the PVN and the bed nucleus of the stria terminalis (BNST) [18]. Estradiol increases PACAP and PAC1R expression in the BNST of ovariectomized (OVX) females relative to vehicle-treated controls [19]. In addition, PACAP expression in the PVN and anterior pituitary is heightened during proestrus - a period dominated by surging estradiol levels in rats [19]. This suggests that activational effects of estradiol may augment the PAC1 receptor-mediated regulation of energy homeostasis in females. Therefore, we hypothesized that $\mathrm{VMN} / \mathrm{PACAP}$ neurons innervate ARC/POMC neurons to provide a source of sex- and diet-sensitive stimulation of POMC neurons through the activation of TRPC5 channels, ultimately serving as a physiologically relevant mechanism underlying the homeostatic control of energy balance.

\section{Materials and Methods}

\section{Animal Models}

Male and female eGFP-POMC mice (18-43 g; 55-93 days of age at terminal harvest) were purchased from Jackson Laboratories (Stock \#009593; C57BL/6 background) and bred in house. Male and female PACAP-Cre mice (18-43 g; 52-144 days of age at terminal harvest) were also purchased from Jackson Laboratories (Stock \#030155; C57BL/6 background) and bred in house as well. For some experiments, hemizygous PACAP-Cre mice were paired with hemizygous eGFP-POMC mice in order to create a double transgenic PACAP-Cre/eGFP-POMC mouse model. Pups were weaned at 21 days of age, and then genotyped at 21-42 days of age using standard PCR protocols. Adult male and female Topeka guinea pigs (580-879 g; 40-79 days of age at terminal harvest) were bred in-house or purchased on demand from Elm Hill Breeding Labs (Clemsford, MA, USA). Animals were housed under a 12:12 $\mathrm{h}$ light/dark cycle (light on at 6 a.m. and off at 6 p.m.), with food and water available ad libitum. On the day of experimentation, MRIs were performed using EchoMRI ${ }^{\mathrm{TM}}-100 \mathrm{H}$ and EchoM$\mathrm{RI}^{\mathrm{TM}}-130$ Body Composition Analyzers for Live Small Animals (Mice) and Organs (EchoMRI LLC, Houston, TX, USA) in order to determine the total fat mass as well as lean mass. Fat dissections were then taken from the perirenal, gonadal, and abdominal regions during terminal harvest. All procedures were approved by the Western University of Health Sciences' IACUC in accordance with institutional guidelines based on NIH standards.

\section{Diet}

Upon genotypic determination, eGFP-POMC, PACAP-Cre, and wild-type mice were immediately subdivided and given continuous access to either a standard rodent chow (Teklad Rodent Diet, Teklad Diets, Madison, WI, USA) from which $18 \%$ of the calories were derived from fat, $24 \%$ from protein, and $58 \%$ from carbohydrates, or an HFD (Research Diets, New Brunswick, NJ,
USA) from which $45 \%$ of calories were derived from fat, $20 \%$ from protein, and 35\% from carbohydrates. All animals were kept on their respective diets for a minimum of 5 weeks prior to experimentation.

\section{Surgical Procedures}

For all experiments, female eGFP-POMC mice and PACAPCre were OVX, while they were under $2 \%$ isoflurane anesthesia 5 days before experimentation. In order to focally inject adeno-associated viral vector (AAV) constructs, PACAP-Cre mice were anesthetized with $2 \%$ isoflurane and placed on a stereotaxic frame (Stoelting, Wood Dale, IL, USA). An incision was made to expose the skull, and a hole was drilled on one or both sides of the midsagittal suture so that an injection needle could be slowly lowered into the dorsomedial subdivision of the VMN (coordinates from bregma: AV, $-0.6 \mathrm{~mm}$; ML, $\pm 0.3 \mathrm{~mm}$; and $\mathrm{DV},-5.6 \mathrm{~mm}$ from dura). Unilateral or bilateral injections of a Cre recombinase-dependent AAV vector respectively containing either cation channel rhodopsin-2 (ChR2 [20]; AAV1.EF1a.DIO.ChR2 (E123A).YFP. WPRE.jGH; $7.2 \times 10^{12}$ genomic copies/mL; $300 \mathrm{~nL}$ total volume; gift from Karl Deisseroth; Addgene plasmid \#35507) or its eYFP blank control (pAAV-Efla-DIO EYFP; $1.0 \times 10^{13} ; 300 \mathrm{~nL}$ total volume; gift from Karl Deisseroth [20]; Addgene plasmid \#27056) or a bilateral injection of a designer receptor exclusively activated by designer drug (DREADD)-containing AAV vector (pAAV-EF1a$\mathrm{DIO}-\mathrm{hM} 3 \mathrm{D}\left(\mathrm{G}_{\mathrm{q}}\right)$-mCherry; $3.8 \times 10^{12}$ genomic copies $/ \mathrm{mL} ; 300 \mathrm{~nL}$ total volume; gift from Bryan Roth; Addgene plasmid \#44361) were given over $2 \mathrm{~min}$. The injection needle remained in place for $10 \mathrm{~min}$ after infusion to allow for diffusion from the tip, and then slowly removed from the brain to reduce inadvertent spread of the virus. Animals were used for experimentation 2-3 weeks after viral injection.

The stereotaxic implantation of either a guide cannula into the ARC or a ferrule into the VMN of the mice was performed similar to that described above. Briefly, once anesthetized, an animal was secured on a stereotaxic frame, and a midline incision was made through the scalp. A hole was then drilled in the skull, through which a 26-gauge guide cannula (Plastics One, Roanoke, VA, USA) was lowered $1 \mathrm{~mm}$ above the ARC using the following coordinates: AP,$-0.6 \mathrm{~mm}$; ML, $\pm 0.3 \mathrm{~mm}$; DV , $-4.9 \mathrm{~mm}$. Ferrules with preattached fibers were lowered into the brain using the following coordinates: AP, $-0.6 \mathrm{~mm}$; ML, $\pm 0.3 \mathrm{~mm}$; and DV, $-5.2 \mathrm{~mm}$ such that the tip's final position was $0.4 \mathrm{~mm}$ above the dorsomedial $\mathrm{VMN}$ in order to avoid excessive damage to the region of interest. Guide cannulas and ferrules were fastened in place with $C \& B$ Metabond dental cement (Parkell, Edgewood, NY, USA) applied to the surgical field. Finally, a stylet was inserted into the guide cannula to keep the lumen patent. The animals were allowed to recover for 1 week prior to the start of experimentation. Only those animals whose injection sites, guide cannulas, or ferrules were accurately placed within the VMN or ARC were used in the present study.

\section{Drugs}

All drugs were purchased from Tocris Bioscience/R\&D Systems (Minneapolis, MN, USA) unless otherwise stated. For electrophysiological experiments, the $\mathrm{Na}^{+}$channel blocker octahydro-12-(hydroxymethyl)-2-imino-5,9: 7,10a-dimethano-10aH-[1,3] dioxocino[6,5-d]pyrimidine-4,7,10,11,12-pentol (Tetrodotoxin, TTX) was prepared as a $1 \mathrm{mM}$ stock solution in UltraPure $\mathrm{H}_{2} \mathrm{O}$, 
and diluted further with artificial CSF (aCSF) to the working concentration of $500 \mathrm{nM}$. PACAP1-38, the PAC1 receptor agonist, was prepared as a $100 \mu \mathrm{M}$ stock solution in UltraPure $\mathrm{H}_{2} \mathrm{O}$ and diluted further with aCSF to the working concentration of $100 \mathrm{nM}$. The PAC1 receptor antagonist, PACAP6-38, was prepared as a $200 \mu \mathrm{M}$ stock solution in UltraPure $\mathrm{H}_{2} \mathrm{O}$ and diluted further with aCSF to the working concentration of $200 \mathrm{nM}$. 2-Aminoethoxydiphenylborane (2-APB), the TRPC channel blocker, was prepared as a 100 mM stock solution in DMSO and diluted further with aCSF to the working concentration of $100 \mu \mathrm{M}$. The selective TRPC5 channel blocker $N$-(2-furanylmethyl)-1-(phenylmethyl)- $1 H$-benzimidazol-2-amine (AC 1903) was dissolved in DMSO to a stock concentration of $30 \mathrm{mM}$, and diluted further with aCSF to the working concentration of $30 \mu \mathrm{M} .1,3,5(10)$-estratrien-3, 17 $\beta$-diol (17 $\beta$ estradiol; $\mathrm{E}_{2}$; Steraloids, RI, USA) was dissolved in punctilious ethanol to a stock concentration of $1 \mathrm{mM}$, which was further diluted to a working concentration of $100 \mathrm{nM}$. The estrogen receptor (ER) antagonist $7 \alpha, 17 \beta$-[9-[(4,4,5,5,5-pentafluoropentyl)sulfinyl]nonyl] estra-1,3,5(10)-triene-3,17-diol (ICI 182,780) was prepared as a $1 \mathrm{mM}$ stock concentration in DMSO that was further diluted with aCSF to a working concentration of $1 \mu \mathrm{M}$. The ERa antagonist 1,3-Bis(4-hydroxyphenyl)-4-methyl-5-[4-(2-piperidinylethoxy) phenol]-1H-pyrazole dihydrochloride (MPP dihydrochloride) was prepared as a $30 \mathrm{mM}$ stock concentration with DMSO and further diluted to a working concentration of $3 \mu \mathrm{M}$.

STX, the $\mathrm{G}_{\mathrm{q}}$-coupled membrane $\mathrm{ER}$ (mER) ligand [21], was prepared as a $1 \mathrm{mM}$ stock solution in DMSO, and further diluted with aCSF to the working concentration of $10 \mathrm{nM}$. The PLC inhibitor 1-[6-[[(17 $\beta)-3$-methoxyestra-1,3, 5(10)-trien-17-yl]amino]hexyl]-1H-pyrrole-2,5-dione (U73122) was prepared as a 20 mM stock solution in DMSO, and further diluted with aCSF to the working concentration of $20 \mu \mathrm{M}$. The inactive U73122 analog 1 -[6-[[(17 $\beta)$-3-methoxyestra-1,3,5(10)-trien-17-yl]amino] hexyl]-2,5-pyrrolidinedione (U73343) was prepared as a $20 \mathrm{mM}$ stock solution in DMSO, and further diluted with aCSF to the working concentration of $20 \mu \mathrm{M}$. The protein kinase A (PKA) inhibitor (9R,10S,12S)-2,3,9,10,11,12-hexahydro-10-hydroxy-9methyl-1-oxo-9,12-epoxy-1H-diindolo[1, 2, 3-fg:3', 2', 1'-kl]pyrrolo[3, 4-i] $[1,6]$ benzodiazocine-10-carboxylic acid, hexyl ester (KT5720) was prepared as a $300 \mu \mathrm{M}$ stock solution in DMSO, and further diluted with aCSF to the working concentration of $300 \mathrm{nM}$. The PKC inhibitor 2-[1-(3-dimethylaminopropyl)indol-3-yl]-3(indol-3-yl) maleimide (GF109203X) was prepared as a $30 \mathrm{~mm}$ stock solution in DMSO and diluted further with aCSF to the working concentration of $30 \mu \mathrm{M}$. The PI3K inhibitor 2-(4morpholinyl)-8-(4-aminopheny)1-4H-1-benzopyran-4-one (PI828) was prepared as a $10 \mathrm{mM}$ stock solution in DMSO and further diluted with aCSF to the working concentration of $10 \mu \mathrm{M}$. Clozapine-N-oxide (CNO) was dissolved in UltraPure $\mathrm{H}_{2} \mathrm{O}$ to a stock concentration of $5 \mathrm{~mm}$, and further diluted with aCSF to a working concentration of $5 \mu \mathrm{M}$.

For all behavioral experiments, PACAP1-38 was prepared as a $150 \mu \mathrm{M}$ stock solution by dissolving it in filtered $0.9 \%$ saline and injected directly into the ARC ( 30 pmol; $0.2 \mu \mathrm{L})$. Estradiol benzoate (EB; Steraloids, Newport, RI, USA) was used in lieu of $E_{2}$ in this context because it is a prodrug requiring biotransformation and therefore prolongs the half-life of $\mathrm{E}_{2}$. It was initially prepared as a $1 \mathrm{mg} / \mathrm{mL}$ stock solution in punctilious ethanol. A known quantity of this stock solution was added to a volume of sesame oil sufficient to produce a final concentration of $20 \mu \mathrm{g} / \mathrm{mL}$ follow- ing evaporation of the ethanol. CNO was dissolved in filtered saline to a stock concentration of $0.3 \mathrm{mg} / \mathrm{mL}$. All aliquots of the stock solutions were stored at either 4 or $-20^{\circ} \mathrm{C}$ until needed for experimentation.

\section{Hypothalamic Slice Preparation}

On the day of experimentation, the animal was briefly anesthetized with $32 \%$ isoflurane and rapidly decapitated. The brain was removed from the skull, and the hypothalamic area was dissected. We then mounted the hypothalamic block on a cutting platform that, for the guinea pig, was secured in a vibratome well filled with ice-cold, oxygenated $\left(95 \% \mathrm{O}_{2}, 5 \% \mathrm{CO}_{2}\right)$ aCSF $(\mathrm{NaCl}, 124$; Na$\mathrm{HCO}_{3}$ 26; dextrose 10, HEPES 10; $\mathrm{KCl} 5 ; \mathrm{NaH}_{2} \mathrm{PO}_{4} 2.6 ; \mathrm{MgSO}_{4} 2$; $\mathrm{CaCl}_{2} 1$; in $\left.\mathrm{mM}\right)$. For the mice, we used a sucrose-based cutting solution $\left(\mathrm{NaHCO}_{3} 26\right.$; dextrose 10, HEPES 10; Sucrose 208; KCl 2; $\mathrm{NaH}_{2} \mathrm{PO}_{4} 1.25 ; \mathrm{MgSO}_{4} 2 ; \mathrm{CaCl}_{2} 1$; in $\mathrm{mM}$ ). Four to five coronal slices $(300 \mu \mathrm{m})$ through the rostrocaudal extent of the ARC were then cut. The slices were transferred to an auxiliary chamber containing oxygenated aCSF at room temperature, and maintained there until the electrophysiological recording.

\section{Electrophysiology}

Whole-cell patch clamp electrophysiological recordings from ARC neurons using biocytin-filled electrodes were performed in hypothalamic slices prepared from intact male guinea pigs as well as intact male and OVX female PACAP-Cre and eGFP-POMC mice. During recordings, the slices were maintained in a chamber perfused with warmed $\left(35^{\circ} \mathrm{C}\right)$, oxygenated aCSF in which the $\mathrm{CaCl}_{2}$ concentration raised to $2 \mathrm{mM}$. Artificial CSF and all drugs (diluted with aCSF) were perfused via peristaltic pump at a rate of $1.5 \mathrm{~mL} / \mathrm{min}$. Patch electrodes were prepared from borosilicate glass (World Precision Instruments, Sarasota, FL, USA; $1.5 \mathrm{~mm}$ OD) pulled on a P-97 Flaming Brown puller (Sutter Instrument Co., Novato, CA, USA), and filled with an internal solution containing the following (in $\mathrm{mM}$ ): potassium gluconate $128 ; \mathrm{NaCl} 10$; $\mathrm{MgCl}_{2}$ 1; EGTA 11; HEPES 10; ATP 1; GTP 0.25; 0.5\% biocytin; adjusted to a $\mathrm{pH}$ of 7.3 with $\mathrm{KOH}$; osmolality: 286-320 mOsm. Electrode resistances varied from 3 to $8 \mathrm{M} \Omega$.

For guinea pig experiments, whole-cell patch clamp recordings were performed using a Multiclamp 700A preamplifier (Axon Instruments, Foster City, CA, USA) that amplified potentials and passed current through the electrode. Membrane currents were recorded in voltage clamp with access resistances ranging from 8 to $20 \mathrm{M} \Omega$. The signals underwent analog-digital conversion via a Digidata 1322A interface coupled to pClamp 10.5 software (Axon instruments). For the mouse experiments, recordings were made on an Olympus BX51 W1 fixed stage microscope outfitted with infrared differential interference contrast video imaging. A Multiclamp 700B preamplifier (Molecular Devices) amplified potentials and passed current through the electrode. Membrane currents underwent analog-digital conversion with a Digidata 1550A interface (Molecular Devices) coupled to pClamp 10.5 software. The access resistance, resting membrane potential, and input resistance were monitored throughout the course of all recordings. If the access resistance deviated $>10 \%$ of the original value, the recording was ended. Low-pass filtering of the currents was conducted at a frequency of $2 \mathrm{kHz}$. The liquid junction potential was calculated to be $-10 \mathrm{mV}$ and corrected for during data analysis using pClamp software. All recordings were performed at a holding potential of -60 $\mathrm{mV}$. 
Fig. 1. Schematic representation of the drug perfusion and photo-stimulation protocols used during electrophysiological recordings. Solution 1 contains any one of the drugs used in this study, with or without TTX. After $3 \mathrm{~min}$, we either switched over to solution 2 containing the contents of solution 1 along with PACAP1-38 or photo-stimulated (10-ms pulses delivered at $20 \mathrm{~Hz}$ for $10 \mathrm{~s}$ ) the slices.

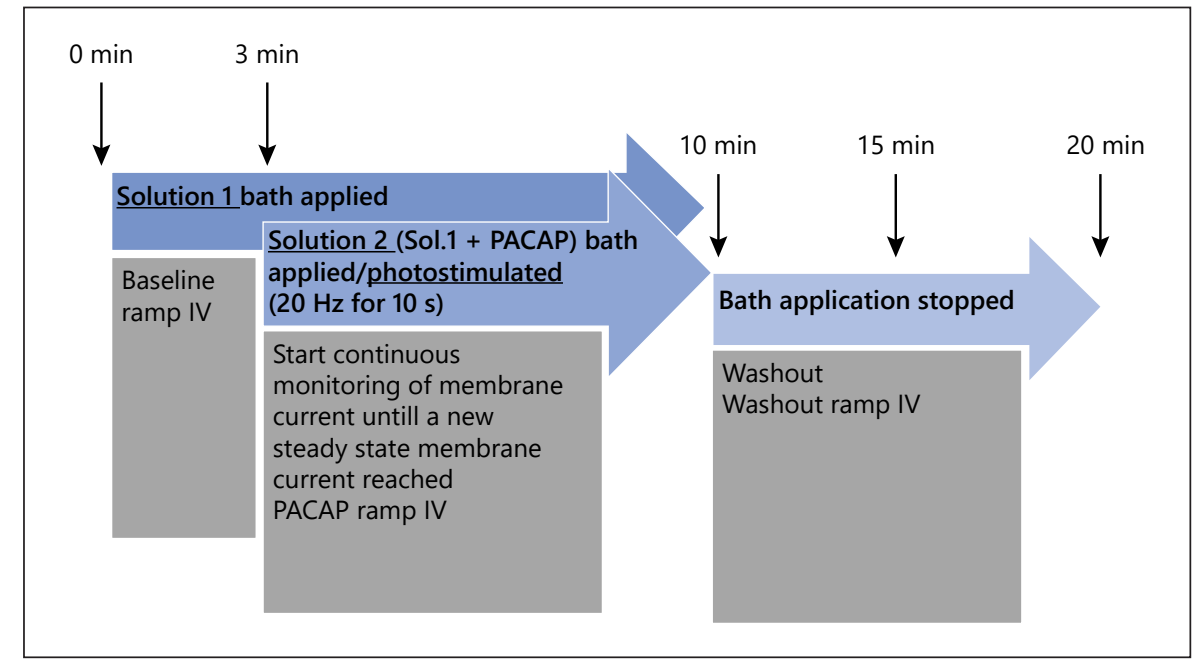

To determine the postsynaptic effects elicited by bath application of PACAP, we first performed recordings in slices from eGFPPOMC mice. For voltage clamp experiments, baseline ramp I/V relationships (from -100 to $+50 \mathrm{mV}$ at a rate of $75 \mathrm{mV}$ per second) were generated in the presence of TTX (500 nM). After the baseline ramp I/V, PACAP1-38 (100 nM) was added along with TTX, and the membrane current (or voltage) was continuously monitored until a new steady-state value was reached (6-8 min after commencing superfusion), at which time a second ramp I/V relationship was generated. During the PACAP washout, the membrane current (or potential) was again monitored until it returned to its original baseline level, at which time a final ramp I/V relationship was taken to ensure reversibility of the PACAP-induced effect. For current clamp experiments, the membrane potential and firing rate were monitored from rest in the absence of TTX until new, PACAP-induced steady-state levels were achieved, and then monitored for an additional 10-20 min to allow for the return to baseline levels. To determine if these postsynaptic effects are PAC1 receptor- and TRPC5 channel-mediated, and positively modulated upon ER activation, these same recordings were performed in slices pretreated with $100 \mu \mathrm{M}$ 2-APB, $30 \mu \mathrm{M}$ AC 1903, $200 \mathrm{nM}$ PACAP6-38, $20 \mu \mathrm{M}$ U73122, $20 \mu \mathrm{M}$ U73433, 300 nM KT5720, $10 \mu \mathrm{M}$ PI828, $30 \mu \mathrm{M}$ GF109203X, $10 \mathrm{nM}$ STX or $100 \mathrm{nM} \mathrm{E}_{2}$, alone and in conjunction with $1 \mu \mathrm{M}$ ICI 182,780 or $3 \mu \mathrm{M}$ MPP.

For the optogenetic experiments, recordings were performed in slices from PACAP-Cre mice that were injected with a ChR2containing viral vector into the VMN 2-3 weeks prior to experimentation. Once glutamatergic PACAP-expressing fibers (visualized with eYFP) impinging on an ARC neuron were encountered, functional synaptic connectivity was ascertained by administering optogenetic stimulation (10-ms pulses delivered at $1,5,10$, or 20 $\mathrm{Hz}$ for $10 \mathrm{~s}$ [22]) from a light-emitting diode blue light source $(470 \mathrm{~nm})$ controlled by a variable $2 \mathrm{~A}$ driver (ThorLabs, Newton, NJ, USA) that directly delivered the light path through the Olympus $\times 40$ water-immersion lens. We also conducted a series of experiments using double transgenic PACAP-Cre/eGFP-POMC animals. For voltage clamp experiments, baseline ramp I/V relationships were generated in the presence of TTX (500 nM) and, in some cases, $100 \mathrm{nM} \mathrm{E}_{2}, 1 \mu \mathrm{M}$ ICI 182,780, or $10 \mathrm{nM}$ STX, respectively.
After generating baseline ramp IVs, we applied the photo-stimulation to generate the slow inward current (in voltage clamp) or depolarization and increase in firing (in current clamp). Once a new steady-state current (or voltage) was reached, we generated a second ramp I/V, after which the membrane current (or voltage) was allowed to return to its original baseline level, at which time a final ramp I/V relationship was taken to ensure reversibility of the optogenetic stimulation. Current clamp experiments were conducted as described in the preceding paragraph. A schematic of the protocol for the drug administration is shown in Figure 1.

\section{Immunohistochemistry}

Slices from eGFP-POMC mice, PACAP-Cre mice, and guinea pigs were processed for immunohistochemistry using various phenotypic markers of ARC POMC or VMN PACAP neurons. Slices were initially fixed with $4 \%$ paraformaldehyde in Sorenson's phosphate buffer ( $\mathrm{pH}$ 7.4) overnight. They were then immersed for 3 days in 20\% sucrose dissolved in Sorensen's buffer, which was changed daily, and frozen in Tissue-Tek embedding medium (Miles Inc., Elk-hart, IN, USA) the next day. Coronal sections (20 $\mu \mathrm{m})$ were cut on a cryostat and mounted on chilled slides. These sections were then washed with $0.1 \mathrm{M}$ sodium phosphate buffer (PBS; $\mathrm{pH} 7.4$ ), and then processed overnight with polyclonal antibodies directed against $\alpha$-melanocyte-stimulating hormone (a-MSH [23]; Immunostar Inc., Hudson, WI, USA; 1:200 dilution), cocaine and amphetamine-regulated transcript (CART [24]; Phoenix Pharmaceuticals Inc., Burlingame, CA, USA; 1:200 dilution), PACAP [25] (Abcam, Cambridge, MA, USA; 1:200), SF-1 [26] (Abcam; 1:300), c-Fos [27] (Santa Cruz Biotechnology, Dallas, TX, USA; 1:500), and/or a monoclonal antibody directed against mCherry [28] (Abcam; 1:500). This was followed the next day by two 15 min washes with PBS, and then a 2-h incubation with biotinylated goat anti-rabbit secondary antibody (Jackson ImmunoResearch Laboratories Inc., West Grove, PA, USA; 1:300). After another series of three 15-min PBS washes, there was a final 2-h overlay with streptavidin-Alexa Flour (AF) 546 or AF 488 (Molecular Probes Inc., Eugene, OR, USA; 1:600), followed by a final series of three 30-min PBS washes and coverslipping the slides. The slides were evaluated using fluorescence immunohistochemistry 
on Zeiss Axioskop 2 Plus (Carl Zeiss, Göttingen, Germany). Transfection efficiency, defined as the number of eYFP- or mCherrypositive cells divided by the number PACAP-positive neurons, as well as the extent of colocalization between PACAP and c-Fos, were evaluated in representative sections from three PACAP-cre mice from each of the appropriate treatment groups. Cell counts taken from an $\sim 0.12 \mathrm{~mm}^{2}$ area within the dorsomedial VMN were determined in triplicate.

\section{Feeding and Metabolic Studies}

The feeding and metabolic studies were performed using a fourstation Comprehensive Lab Animal Monitoring System (CLAMS; Columbus Instruments, Columbus, Ohio, USA) from which we monitored cumulative food intake, meal size, meal frequency rate of consumption $(\mathrm{kcal} / \mathrm{s})$, and several measures of energy expenditure $\left(\mathrm{O}_{2}\right.$ consumption, $\mathrm{CO}_{2}$ production, and respiratory exchange ratio [RER] and metabolic heat production). These studies were conducted under conditions in which food and water were available ad libitum. An electronic balance measured the amount of food contained within each food trough and the amount consumed by each animal. Each food trough was equipped with an outer spillage container that effectively mitigated against overestimating the actual amount consumed. The animals were allowed to acclimate in their CLAMS chamber over a 3-day period. Each day, they were weighed, handled, and returned to their respective chambers. After the 3-day acclimation session, we initiated the 5-day monitoring phase during which the animals were weighed, injected each day at 4:00 p.m. (2-3 h in advance of the nocturnal peak in energy consumption) with either PACAP1-38 (30 pmol), or its $0.9 \%$ saline vehicle $(0.2 \mu \mathrm{L})$ administered directly into the ARC. For OVX females, either EB $(20 \mu \mathrm{g} / \mathrm{kg}$ s.c.) or its sesame oil vehicle $(1 \mathrm{~mL} / \mathrm{kg}$ s.c.) were delivered every other day, starting with acclimation day 2 and through experiment day 5. For the chemogenetic studies, mice were injected with $\mathrm{CNO}(0.3 \mathrm{mg} / \mathrm{kg}$ s.c. $)$ or its $0.9 \%$ saline vehicle $(1 \mathrm{~mL} / \mathrm{kg}$ s.c. $)$ at the same time. For the optogenetic experiments, OVX animals injected with either EB or sesame oil were connected to a PlexBright 4-channel optogenetic controller (Plexon, Dallas, TX, USA). The fiber cables are then magnetically attached to each individual ferrule. Once connected, each animal is photostimulated $(10-\mathrm{ms}$ pulses delivered at $20 \mathrm{~Hz}$ for $1 \mathrm{~s}$, every $4 \mathrm{~s}$ [29]) for $1 \mathrm{~h}$ while simultaneously being monitored for each of the above-described parameters of energy balance over a 5-day span.

Cumulative food intake was taken as the total amount of food consumed at 1, 2, 4, and $8 \mathrm{~h}$ after either PACAP or vehicle admin-

Fig. 2. The PACAP-induced inward current is significantly attenuated by PAC1R blockade and TRPC5 inhibition. a A $\times 4$ image taken from a male eGFP-POMC mouse showing the area of fluorescence located in the ARC. The eGFP fluorescence signal from a recorded neuron in the ARC (b) and a differential interference contrast (DIC) image $(\mathbf{c})(\times 40)$ showing the electrode impinging on that same neuron. d A $\times 20$ image depicting the a-MSH immunoreactivity visualized with AF546. e Another $\times 20$ image showing the eGFP signal in ARC neurons. f Composite overlay of both AF546 and a-MSH. g, h Representative current traces seen in the presence of PACAP, which causes an inward current in intact male eGFP-POMC mice and guinea pigs that reversed polarity around $-20 \mathrm{mV}$ and is associated with an in- istration. Meal size is the amount of food eaten in a given hour divided by the number of meals in that same hour, and meal frequency is the number of bouts in a given hour. Meal duration is the length of time of which food was eaten in a given hour. The rate of consumption is calculated as a meal size per meal duration in a given hour. The parameters of energy intake, meal pattern, and energy expenditure were continuously written to a computer via an $\mathrm{A} / \mathrm{D}$ converter.

\section{Statistical Analyses}

Variance homogeneity was evaluated using Levene's test. Comparisons between two groups were made with the Student's $t$ test and the Mann-Whitney U test. Comparisons made between more than two groups were performed using either the one-way, repeated-measures, or rank-transformed multifactorial analysis of variance (ANOVA) followed by the least significant difference (LSD) test, or alternatively via the Kruskal-Wallis test followed by the median-notched box-and-whisker analysis. Differences were considered statistically significant if the alpha probability was 0.05 or less.

\section{Results and Figures}

\section{Experiment 1: In vitro Effects of Exogenous PACAP} on the Excitability of Anorexigenic POMC Neurons in Male and Female Mice

The PACAP-Induced Inward Current Is Significantly Attenuated by TRPC5 Inhibition and PAC1R

\section{Blockade}

Previous studies have shown that central administration of PACAP induced c-Fos mRNA expression and increased the proportion of ARC POMC neurons expressing c-Fos mRNA [12]. It has also been shown that POMC mRNA levels in the ARC of PACAP receptor (PAC1R) knockout mice was reduced as compared with wild-type animals, which indicates that PACAP excites POMC neurons via activation of $\mathrm{PAC} 1$ receptors [12]. Given that both leptin and insulin excite POMC neurons via activation of TRPC5 channels, we examined if PACAP can

crease in conductance measured between -60 and $-80 \mathrm{mV}(\mathbf{m})$. These effects were markedly attenuated in the presence of the PAC1 receptor antagonist PACAP6-38 $(\mathbf{i}, \mathbf{I}, \mathbf{m})$, the nonselective TRPC channel blocker 2APB $(\mathbf{j}, \mathbf{I}, \mathbf{m})$, and the selective TRPC5 channel inhibitor AC 1903 (k-m). The breaks in the traces represent the time necessary to conduct the second ramp I/V. Bars represent means, and lines 1 SEM of the change in membrane current $(\Delta \mathrm{I})$ and slope conductance $(\Delta \mathrm{g})$ caused by PACAP, alone and in conjunction with PACAP6-38, 2-APB, or AC 1903. Numbers centered above or below the data bars represent the number of recorded cells, whereas those parenthetically enclosed represent the number of animals. ${ }^{*} p<0.05$, relative to intact males, one-way ANOVA/LSD. (For figure see next page.) 

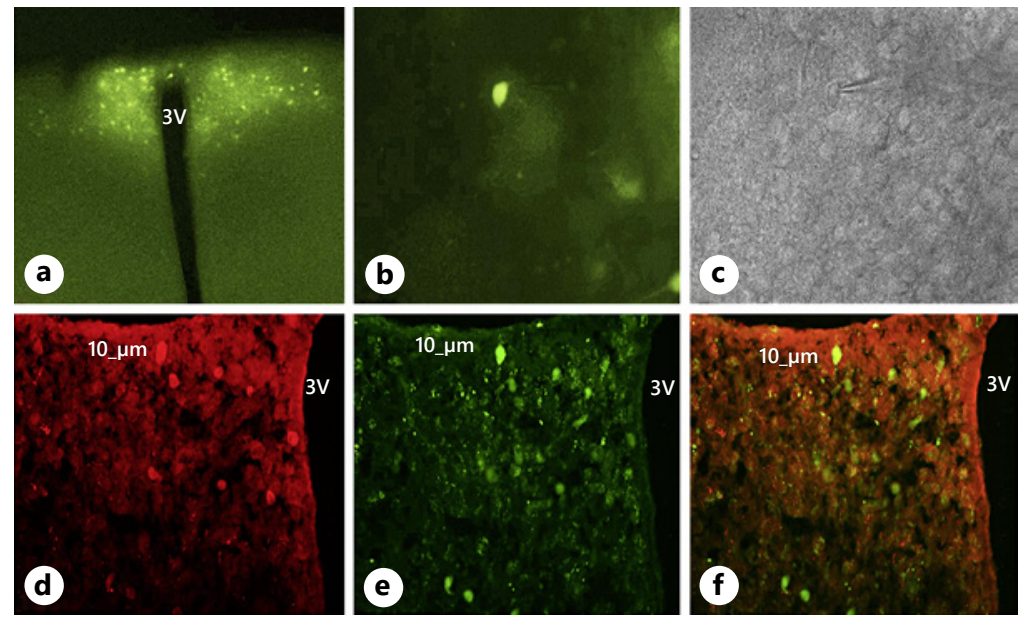

d-f: $\alpha-M S H$ (red) and eGFP (green)

Intact male eGFP-POMC mouse

$\Vdash \frac{\operatorname{TTX}(500 \mathrm{~nm})}{\operatorname{TTX}+\operatorname{PACAP}(100 \mathrm{~nm})}$

Intact male guinea pig
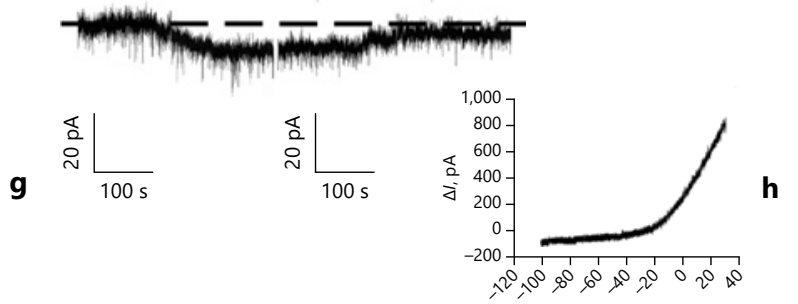

$\frac{\operatorname{TTX}(500 \mathrm{~nm})}{\operatorname{TTX}+\text { PACAP (100 nM) }}$

$\frac{\text { Intact male eGFP-POMC mouse }}{\text { TTX (500 nM) + PACAP6-38 (200 nм) }}$

$\overline{\text { TTX + PACAP6-38 + PACAP (100 nM) }}$

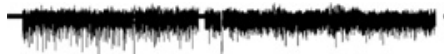

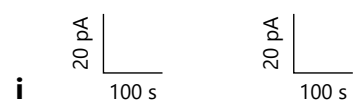

$\frac{\text { Intact male eGFP-POMC mouse }}{\operatorname{TTX}(500 \mathrm{nM})+2-\mathrm{APB}(100 \mu}$

$\sqrt{\mathrm{TTX}+2-\mathrm{APB}+\operatorname{PACAP}(100 \mathrm{~nm})}$
Intact male eGFP-POMC mouse

TTX (500 nм) + AC $1903(30 \mu \mathrm{M})$

$\overline{\text { TTX + AC } 1903(30 \mu \mathrm{m})}+$ PACAP (100 nm)
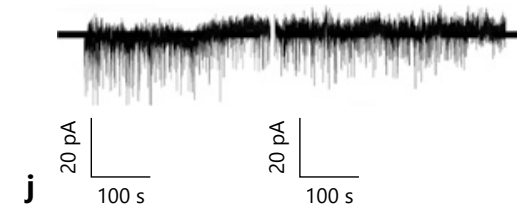

衣

100 s

京

$100 \mathrm{~s}$ 


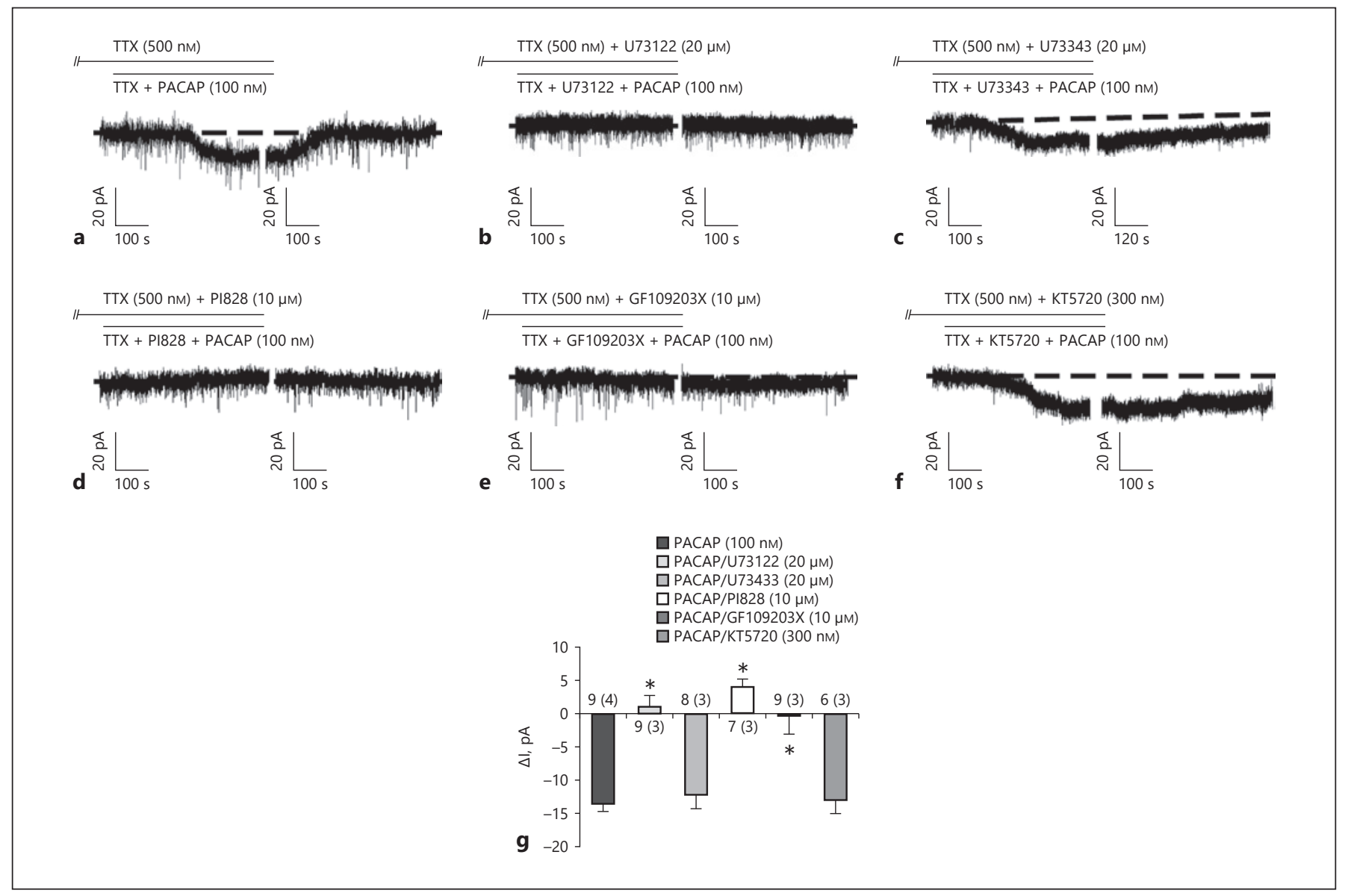

Fig. 3. The PACAP-induced inward current in POMC neurons is mediated by activation of PLC, PI3K and PKC, but not PKA. Representative traces showing the PACAP-induced inward current (a) that is blocked by the PLC inhibitor U73122 (b), but not the inactive isomer U73433 (c). The PACAP-induced inward current is also markedly attenuated by the PI3K inhibitor PI828 (d) as well as the PKC inhibitor GF109203X (e). f By contrast, the PACAP-induced inward current is unaffected by the PKA inhibitor KT5720. The breaks in the traces represent the time necessary to conduct the sec-

stimulate POMC neurons via activation of PAC1 receptors and TRPC5 channels. To this end, we coapplied PACAP alone or in conjunction with either the PAC1 receptor antagonist PACAP6-38 or one of two TRPC channel blockers: 2-APB or AC 1903. We recorded a total of 102 ARC POMC neurons from male and OVX female eGFPPOMC mice. Recordings were taken from eGFP-expressing neurons, the vast preponderance of which were immunopositive for various markers of POMC neurons (Fig. 2a-f). PACAP (100 nM) caused an inward current in intact males that reversed polarity around $-20 \mathrm{mV}$ and was associated with an increase in conductance measured between -60 and $-80 \mathrm{mV}$ (Fig. $2 \mathrm{~g}$ ). Furthermore, we ond ramp I/V. g The composite bar graph further illustrates the diminution of the PACAP-induced inward current seen in the presence of inhibitors of PLC, PI3K, and PKC but not PKA. Bars represent means, and lines 1 SEM of the change in membrane current $(\Delta \mathrm{I})$ caused by PACAP, alone in conjunction with U73122, U73433, PI828, GF109203X, and KT5720. Numbers centered above or below the data bars represent the number of recorded cells, whereas those parenthetically enclosed represent the number of animals. ${ }^{*} p<0.05$, relative to intact male, one-way ANOVA/LSD.

found that the PACAP-induced inward current seen in male eGFP-POMC mice was virtually identical to that observed in POMC neurons from male guinea pigs (Fig. 2h). These effects were markedly attenuated in the presence of the PAC1 receptor antagonist PACAP6-38 (200 nM [30, 31]; Fig. 2i), the nonselective TRPC channel blocker 2APB (100 $\mu \mathrm{M}$ [17]; Fig. 2j), and the selective TRPC5 channel inhibitor AC 1903 (30 $\mu \mathrm{M}$ [32]; Fig. 2k-1; oneway ANOVA/LSD: $F_{\text {ratio }}=24.03, \mathrm{df}=4, p<0.0001$; Fig. $2 \mathrm{~m}$; one-way ANOVA/LSD: $F_{\text {ratio }}=4.00, \mathrm{df}=3, p<$ $0.03)$ in male eGFP-POMC mice. These data illustrate that PACAP activates ARC POMC neurons due to the activation of the PAC1 receptor and TRPC channels. 


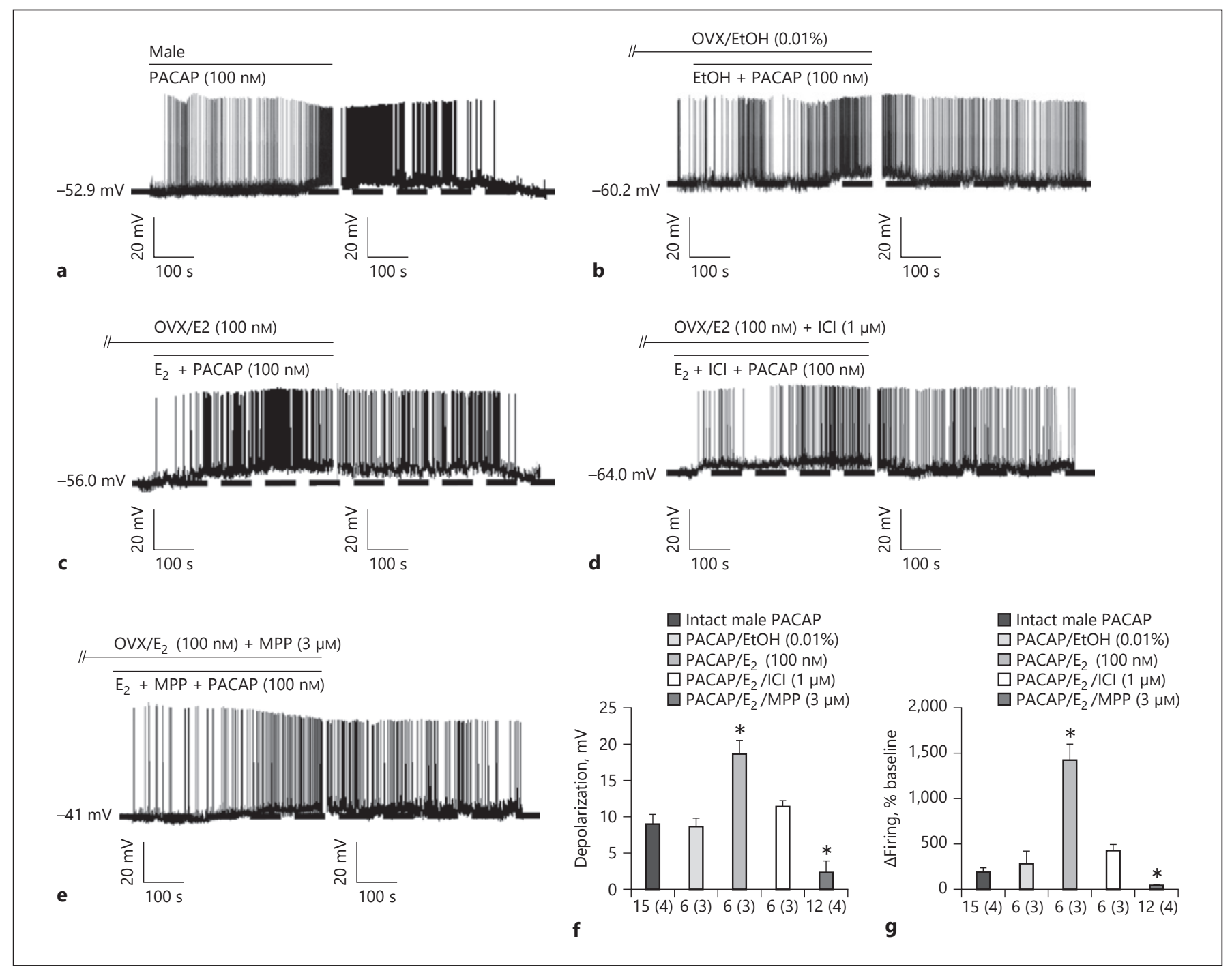

Fig. 4. The PACAP-induced inward current is associated with a depolarization and an increase in firing, which is further enhanced by $\mathrm{E}_{2}$ acting at ERa. a Representative trace of a current clamp recording in a slice from an intact male eGFP-POMC mouse showing the reversible depolarization and increase in firing. b Comparable effects are seen during recordings in vehicle pretreated slices from OVX females. $\mathrm{E}_{2}$ significantly potentiated the PACAP-induced depolarization and increase in firing (c), which was abolished by the broad-spectrum ER antagonist ICI 182,780 (d) and the ERa-selective antagonist MPP (e). The

The PACAP-Induced Inward Current in POMC Neurons Is Mediated by Activation of PLC, PI3K, and PKC but Not PKA

We then wanted to determine the signal transduction pathway coupling the PAC1 receptor with TRPC5 channels, and as such we utilized many inhibitors of putative downstream signaling molecules. When PACAP was co- breaks in the traces represent the time necessary to conduct the second ramp I/V. These effects are summarized in the composite bar graphs seen in $\mathbf{f}$ and $\mathbf{g}$. Bars represent means, and lines 1 SEM of the depolarization magnitude $(\mathrm{mV} ; \mathbf{f})$ and the change in firing $(\mathbf{g})$. Numbers centered below the data bars depict the number of recorded cells, whereas those parenthetically enclosed represent the number of animals. $* p<0.05$, relative to intact male and EtOH-treated, OVX female slices, one-way ANOVA/LSD (f), Kruskal-Wallis/median-notched box-andwhisker analysis $(\mathbf{g})$. 

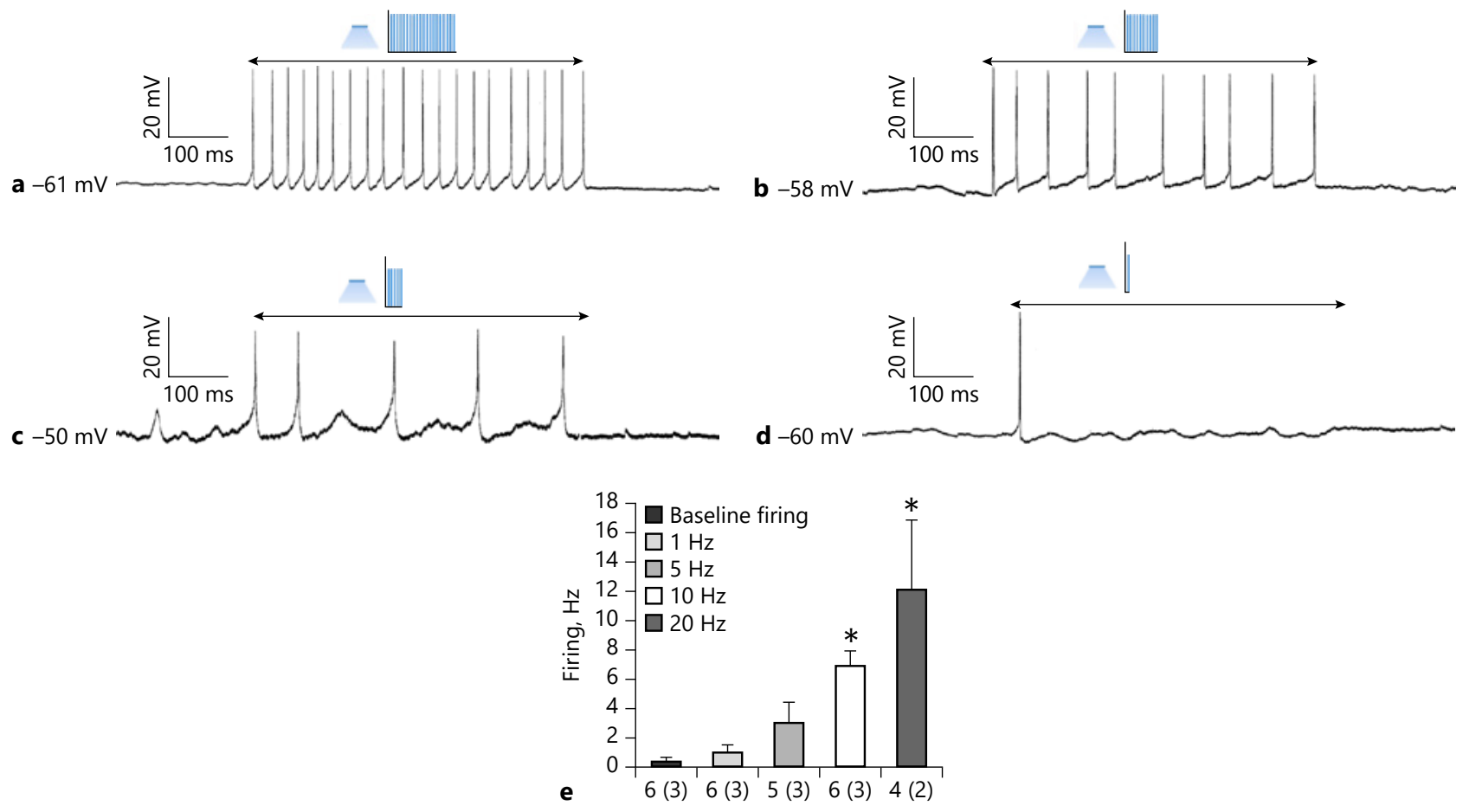

Fig. 5. Optogenetic stimulation of VMN PACAP neurons elicits a frequency-dependent increase in firing. Representative traces show action potentials generated during a 1-s excerpt of optogenetic stimulation delivered at $20 \mathrm{~Hz}(\mathbf{a}), 10 \mathrm{~Hz}(\mathbf{b}), 5 \mathrm{~Hz}(\mathbf{c})$, and $1 \mathrm{~Hz}$ (d; 10 -ms pulses, $10 \mathrm{~s}$ total duration). The composite bar graph in e illustrates the graded increase in firing rate caused by the varying frequencies of optogenetic stimulation. Numbers centered above the data bars denote the number of recorded cells, whereas those parenthetically enclosed depict the number of animals. ${ }^{*} p<0.05$ relative to baseline, one-way ANOVA/LSD.
Fig. 3a, e, g). On the other hand, the PACAP-induced inward current persisted in the presence of the PKA inhibitor KT5720 (300 nM [33]; Fig. 3a, f, g; one-way ANOVA/ LSD: $\left.F_{\text {ratio }}=13.73, \mathrm{df}=5, p<0.0001\right)$. These data illustrate that PACAP binds to $\mathrm{G}_{\mathrm{q}^{-}}$but not $\mathrm{G}_{\mathrm{s}}$-coupled PAC1 receptors to activate TRPC5 channels in POMC neurons via a signal transduction pathway that also involves PI3K.

The PACAP-Induced Inward Current Is Associated with a Depolarization and an Increase in Firing, Which Is Further Enhanced by $\mathrm{E}_{2}$ Acting at ERa

Our voltage clamp recordings showed that the PACAP-induced inward current of ARC POMC neurons is attributable to the stimulation of $\mathrm{PAC} 1$ receptors and subsequent activation of TRPC 5 channels. Current clamp recordings in slices from intact male eGFP-POMC mice (Fig. 4a) show that this inward current is associated with a depolarization and an increase in firing frequency (Fig. 4f, g). Recording in vehicle pretreated slices from OVX females uncovered a comparable PACAP-induced depolarization and increase in firing frequency (Fig. $4 \mathrm{~b}$, $\mathrm{f}, \mathrm{g})$. Interestingly, $\mathrm{E}_{2}$ (100 $\mathrm{nm}[33]$ ) significantly potentiated the depolarization and increase in firing caused by PACAP during recordings of POMC neurons in slices from OVX females; effects that were abolished by the broad-spectrum ER antagonist ICI 182,780 (1 $\mu \mathrm{M}$ [33]) and the ERa-selective antagonist MPP dihydrochloride ( $3 \mu \mathrm{M}$ [35]; Fig. 4c-e, f; one-way ANOVA/LSD: $F_{\text {ratio }}=$ 20.97, $\mathrm{df}=4, p<0.0001$; Fig. 4g; Kruskal-Wallis/mediannotched box-and-whisker plot, test statistic $=16.86, p<$ $0.003)$. These data indicate that the PACAP-induced increase in the excitability of ARC POMC neurons is positively modulated by ER $\alpha$-mediated activational effects of $\mathrm{E}_{2}$. 


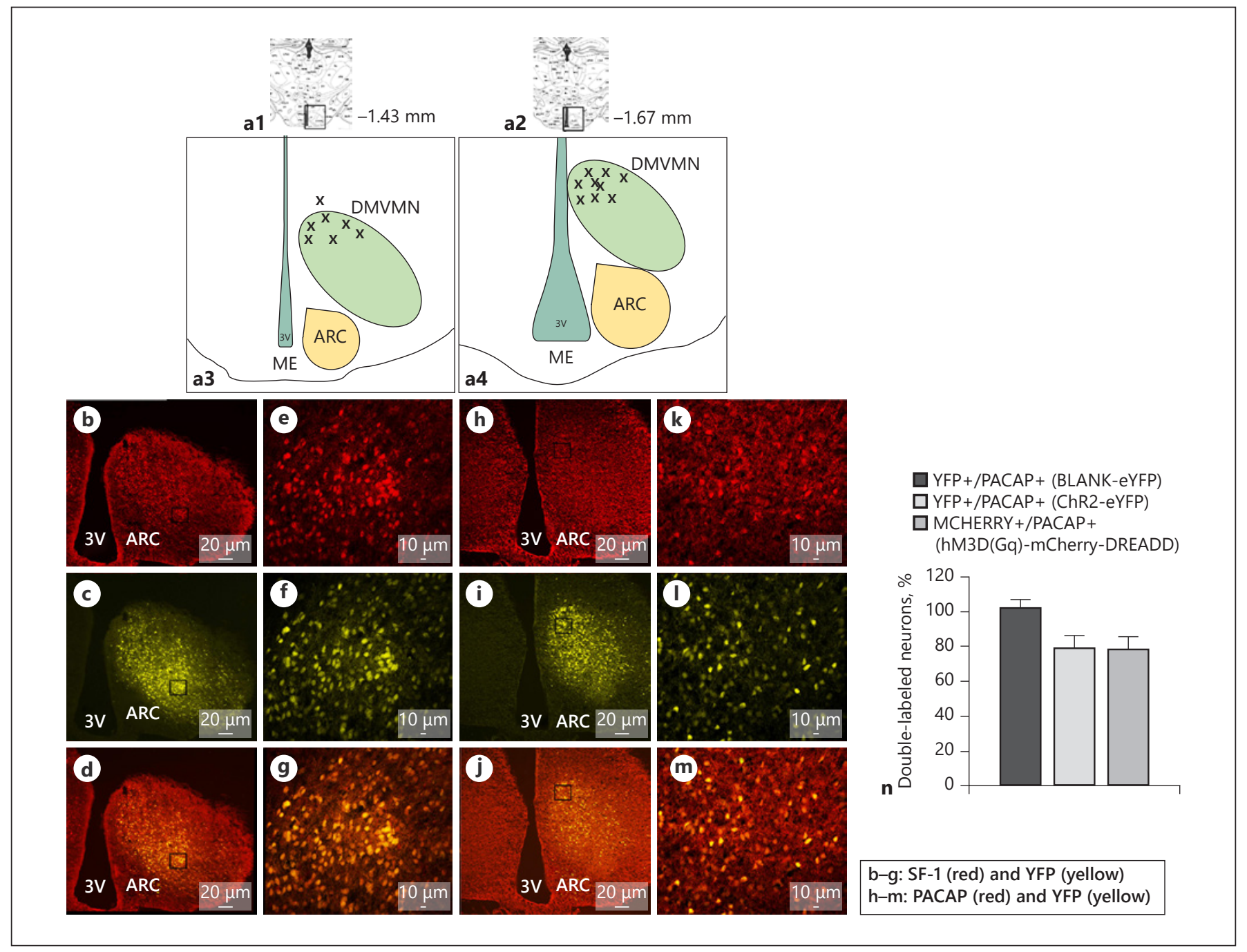

Fig. 6. The eYFP reporter is expressed with high fidelity in SF-1 and PACAP neurons following accurate injections of ChR2 into the dorsomedial VMN (DMVMN). a1-a4, Coronal schematics illustrating the accuracy of our AAV injection site in the DMVMN of animals designated for electrophysiology experiments. $\mathbf{b}-\mathbf{d}, \mathbf{h}-\mathbf{j}$ Low-power $(\times 5)$ photomicrographs showing SF-1 (b) and PACAP (h) immunostaining (top row; visualized with AF-546), eYFP la-

Experiment 2: In vitro Studies of Selective Activation of VMN PACAP Neurons on the Excitability of Anorexigenic POMC Neurons in Male and Female Mice Optogenetic Photostimulation of VMN PACAP Neurons Elicits an Inward Current That Depolarizes POMC Neurons and Increases Their Firing, Which Is Further Enhanced by $\mathrm{E}_{2}$ Acting at $\mathrm{G}_{\mathrm{q}}$-coupled mERs Thus far, we have shown that exogenous PACAP excites $\mathrm{POMC}$ neurons by activating $\mathrm{PAC1}$ receptors and TRPC5 channels. We then wanted to ascertain the origin beling ( $\mathbf{c}, \mathbf{i}$, middle row), and composite overlay ( $\mathbf{d}, \mathbf{j}$, bottom row). $\mathbf{e}-\mathbf{g}, \mathbf{k}-\mathbf{m}$ Higher-power $(\times 20)$ photomicrographs taken from the area enclosed by the rectangle shown in $\mathbf{b}-\mathbf{d}, \mathbf{h}-\mathbf{j}$, respectively. n Bar graph depicting the AAV transfection efficiency in PACAP neurons for each of the three vectors used in the present study. Bars represent means and lines 1 SEM. 


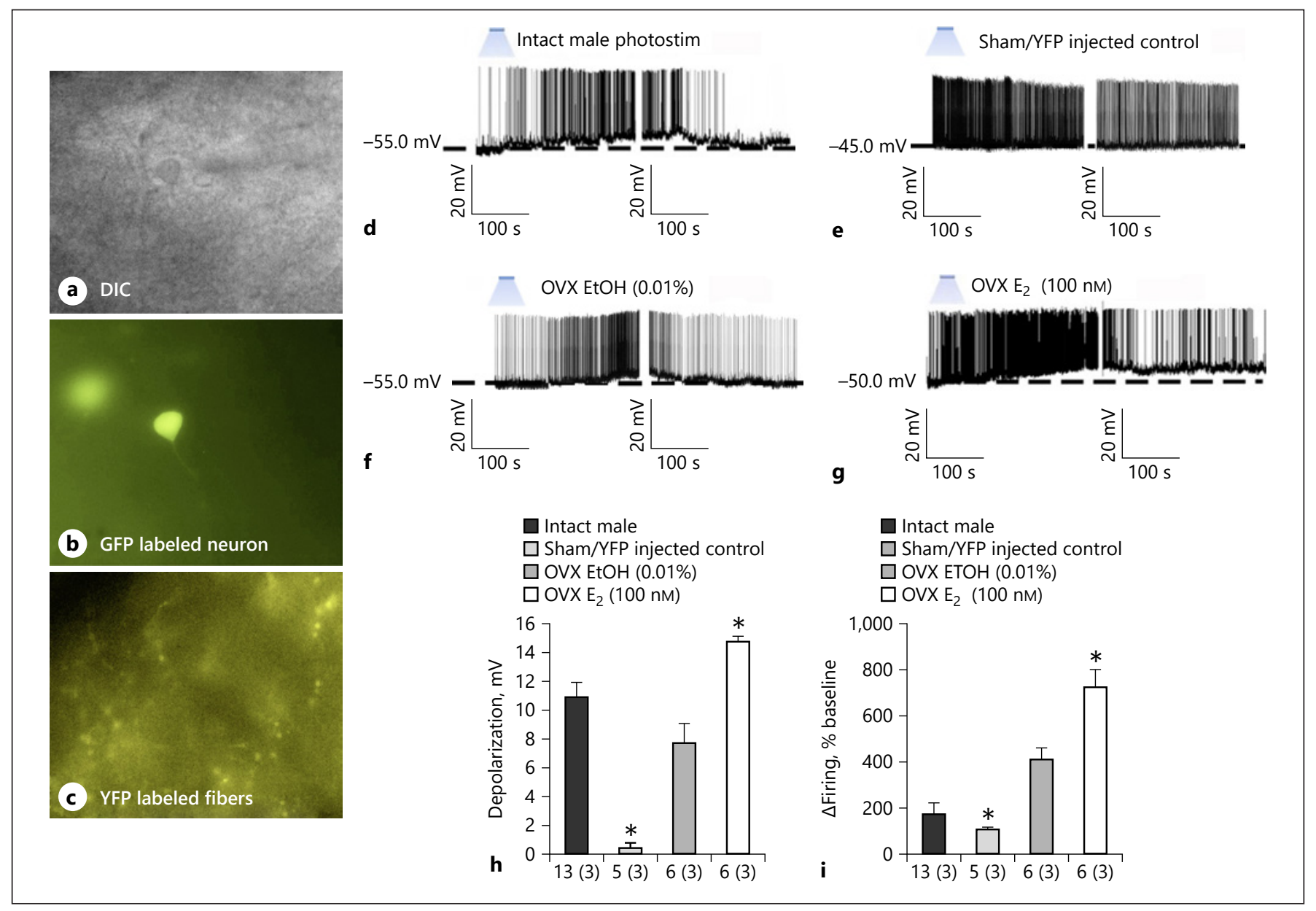

Fig. 7. Optogenetic stimulation of VMN PACAP neurons depolarizes POMC neurons and increases their firing, which is further heightened by $E_{2}$. $\mathbf{a} \times 40$ DIC image of an ARC POMC neuron taken from a PACAP-Cre/eGFP POMC mouse and the eGFP fluorescence signal from the same neuron (b). $\mathbf{c} \times 40$ image showing the eYFP-labeled fibers in the immediate vicinity of the recorded neuron. Photostimulation of male VMN PACAP neurons $(\mathbf{d}, \mathbf{h}, \mathbf{i})$ produces a reversible depolarization and increase in firing in ARC POMC neurons that are not seen in sham- or eYFP blank-injected controls $(\mathbf{e}, \mathbf{h}, \mathbf{i})$. The light-induced depolarizations and increases

for $10 \mathrm{~s}$ ) could drive the release of endogenous PACAP at VMN PACAP/ARC POMC synapses. To this end, we recorded from 65 ARC neurons from male and OVX female PACAP-Cre mice. Two to 3 weeks after delivery into the dorsomedial region of the VMN (Fig. 6a1-a4), ChR2 and its eYFP reporter were expressed in the considerable majority of both SF-1 and PACAP neurons in the VMN (Fig. $6 \mathrm{~b}-\mathrm{m}$ ), which further demonstrates that PACAP is expressed in SF-1 neurons. The $\mathrm{hM} 3 \mathrm{D}\left(\mathrm{G}_{\mathrm{q}}\right)$-mCherryDREADD transfected VMN PACAP neurons with nearly identical efficiency (Fig. 6n). We saw that photostimula- in firing observed during recordings from vehicle pretreated slices from OVX females $(\mathbf{f}, \mathbf{h}, \mathbf{i})$ are significantly enhanced by E2 $(\mathbf{g}-\mathbf{i})$. The breaks in the traces represent the time necessary to conduct the second ramp I/V. Bars represent means, and lines 1 SEM of the depolarization magnitude ( $\mathrm{mV} ; \mathbf{h})$ and changes in firing (i). Numbers centered below the data bars illustrate the number of recorded cells, whereas those parenthetically enclosed represent the number of animals. ${ }^{*} p<0.05$, relative to intact male and $\mathrm{EtOH}-$ treated OVX female slices, one-way ANOVA/LSD (h), KruskalWallis/median-notched box-and-whisker analysis (i).

tion of VMN PACAP neurons depolarizes ARC neurons and increases their firing, effects that were faithfully recapitulated in a series of recordings from PACAP-Cre/eGFP POMC mice (Fig. 7a-d, h, i) but not apparent in sham- or eYFP blank-injected controls (Fig. 7e, h, i). Comparable light-induced depolarizations and increases in firing were observed during recordings from vehicle pretreated slices from OVX females (Fig. 7f, h, i). When estradiol was applied immediately prior to photostimulation, the resultant depolarization and increase in firing were enhanced in a manner similar to that seen with exogenously applied PA- 


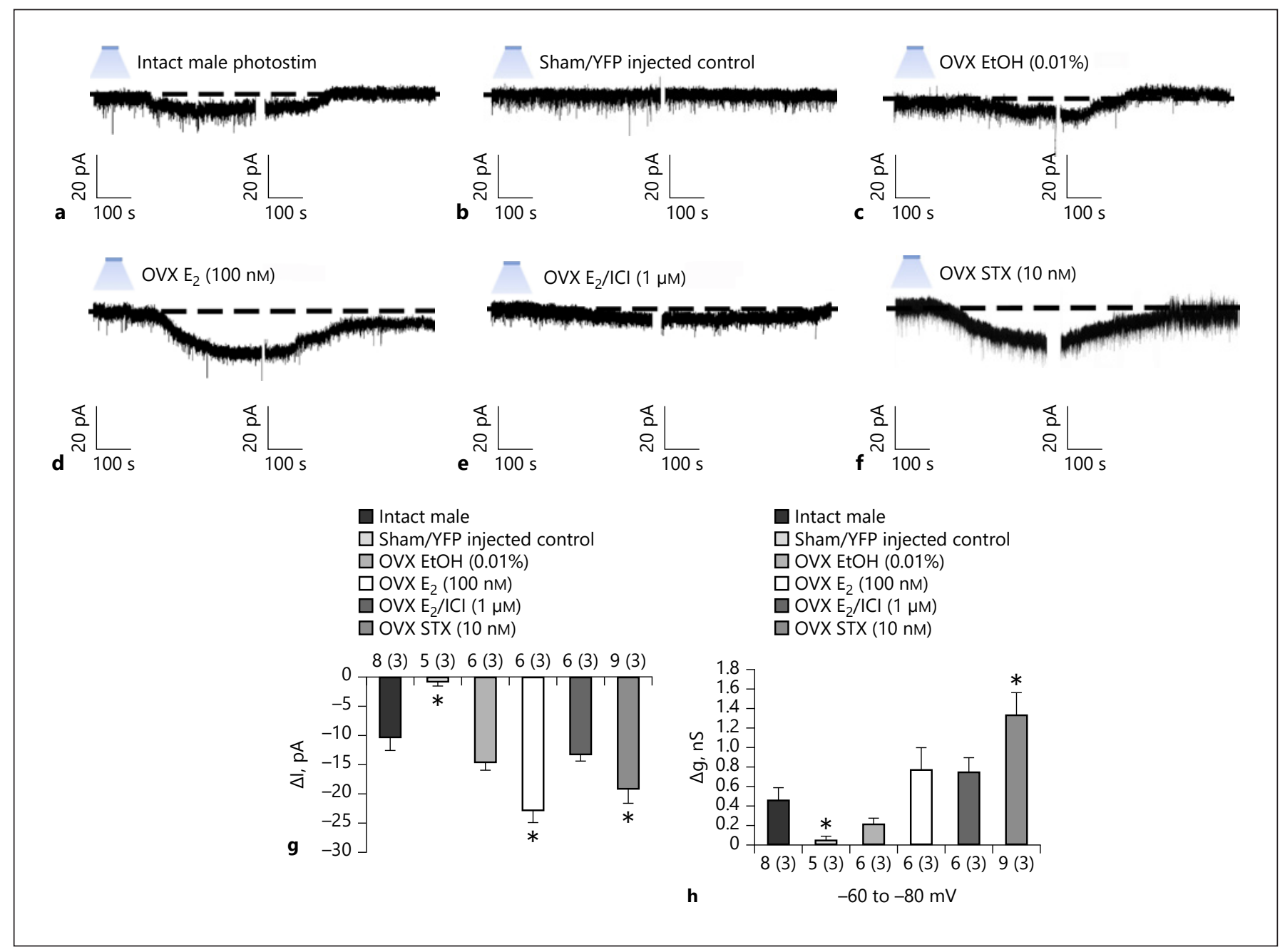

Fig. 8. The estrogenic enhancement of VMN PACAP optogenetic stimulation and the resultant excitation of ARC POMC neurons are mediated by $\mathrm{G}_{\mathrm{q}}$-coupled mERs. Voltage clamp recordings showing a light-induced inward current in male POMC neurons (a), an effect that is not encountered in sham-or eYFP blank-injected controls (b). The inward current observed during recordings in vehicle pretreated slices from OVX females (c) is clearly potentiated by $\mathrm{E}_{2}(\mathbf{d})$, and this effect is abrogated by ICI $182,780(\mathbf{e})$ and mirrored by the $\mathrm{G}_{\mathrm{q}}$-coupled mER ligand STX (f; $n=9)$. The breaks in the traces represent the time necessary to

CAP (Fig. 7g, h; one-way ANOVA/LSD: $F_{\text {ratio }}=10.65$, $\mathrm{df}=3, p<0.0004$; Fig. 7i; Kruskal-Wallis/median-notched box-and-whisker plot, test statistic $=10.36, p<0.02$ ). Likewise, in voltage clamp recordings, $\mathrm{E}_{2}$ augmented the inward current caused by light-induced activation of ChR2 relative to that seen during recordings in slices from males and vehicle-treated slices from OVX females (Fig. 8a-d, g, $h)$. This potentiating effect of $E_{2}$ was abrogated in the pres- conduct the second ramp I/V. g, h The composite bar graphs serve to further illustrate that $\mathrm{E}_{2}$ enhances excitatory neurotransmission at VMN PACAP/ARC POMC synapses via activation of $\mathrm{G}_{\mathrm{q}}$-coupled mERs. Bars represent means, and lines 1 SEM of the change in membrane current $(\Delta \mathrm{I} ; \mathbf{g})$ and slope conductance $(\Delta \mathrm{g} ; \mathbf{h})$. Numbers centered above or below the data bars depict the number of recorded cells, whereas those parenthetically enclosed show the number of animals. ${ }^{*} p<0.05$, relative to intact male and EtOH-treated OVX female slices, one-way ANOVA/LSD. 

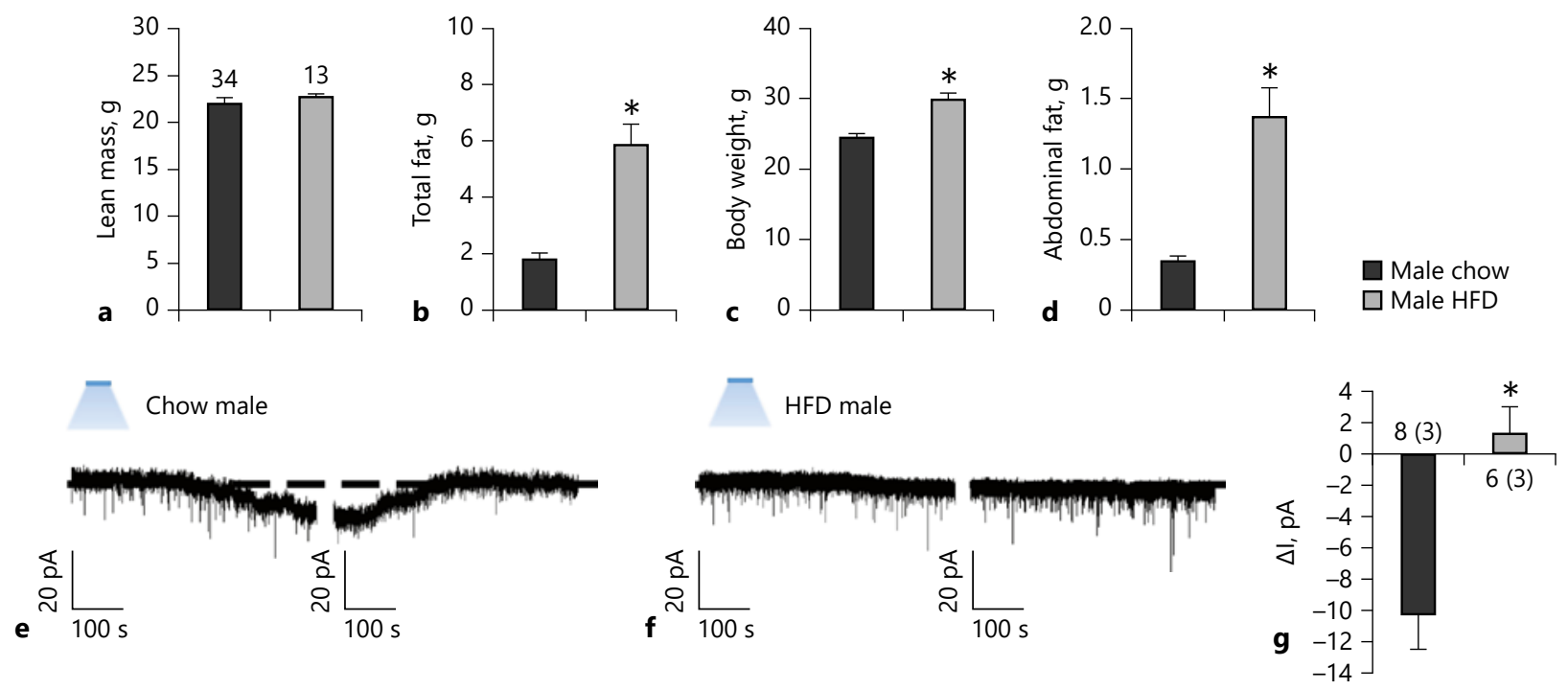

Fig. 9. The excitatory effects of VMN PACAP neurons on ARC POMC neurons are markedly blunted by long-term HFD exposure. Composite bar graphs of lean mass (a), total fat (b), body weight (c), and abdominal fat (d) of chow-fed $(n=34)$ and HFDfed animals. Representative traces showing that the light-induced inward current seen in chow-fed males (e) is markedly diminished in HFD-fed males (f). The breaks in the traces represent the time necessary to conduct the second ramp I/V. g The composite bar

\section{PACAP's Excitatory Effects Are Reversed by}

Long-Term HFD Exposure

We and others have shown previously that long-term exposure to HFD produces central insulin resistance that is sexually differentiated and associated with attenuated anorexigenic signaling within VMN SF-1/ARC POMC synapses [37-39]. We therefore wanted to examine whether a similar duration of HFD exposure could dampen anorexigenic transmission at VMN PACAP/ARC POMC synapses. The HFD significantly increased body weight and adiposity (Fig. 9a; Student's $t$ test: $t=-0.71$, $p<0.5$; Fig. 9b; Student's $t$ test: $t=-6.52, p<1.3 \mathrm{E}-7$; Fig. 9c; Student's $t$ test: $t=-4.87, p<0.00002$; Fig. 9d; Student's $t$ test: $t=-7.19, p<4.3 \mathrm{E}-9)$, and optogenetic voltage clamp recordings from these obese males revealed that the light-induced inward current was markedly diminished (Fig. 9e-g; Student's $t$ test: $t=-3.85, p<0.003$ ). These results show that excitatory neurotransmission occurring at VMN PACAP/ARC POMC synapses is greatly compromised under conditions of diet-induced obesity/ insulin resistance. graph summarizes the derangement in excitatory neurotransmission occurring at VMN PACAP/ARC POMC synapses associated with diet-induced obesity/insulin resistance. Bars represent means, and lines 1 SEM of the change in membrane current $(\Delta \mathrm{I})$. Numbers centered above or below the data bars illustrate the number of recorded cells, whereas those parenthetically enclosed show the number of animals. ${ }^{*} p<0.05$, relative to chow-fed males, Student's $t$ test.

\section{Experiment 3: In vivo Effects of Excitatory}

Neurotransmission at VMN PACAP/ARC POMC

Synapses on Energy Intake, Meal Pattern, and Energy

Expenditure

Direct Injection of PACAP into the ARC

Significantly Decreases Energy Intake and Increases

Energy Expenditure in a Diet-Sensitive Manner

So far in our in vitro studies, we have found that both exogenous PACAP and endogenous PACAP emanating from VMN neurons excite POMC neurons via activation of $\mathrm{G}_{\mathrm{q}}$-coupled PAC1 receptors and TRPC5 channels. We next wanted to ascertain the importance of these VMN PACAP/ARC POMC synapses in the regulation of energy balance, along with the modulatory influence of diet, with an in vivo approach. Here, we took wild-type male mice and surgically implanted a guide cannula directly above the ARC. After 2 weeks of recovery, animals were treated intraARC with either $0.9 \%$ saline vehicle $(0.2 \mu \mathrm{L})$ or PACAP $(30$ pmol $[3,11])$ every day at $4 \mathrm{pm}$ for the 5 -day duration of the behavioral study. In chow-fed animals, PACAP significantly decreased food intake from 1 to $4 \mathrm{~h}$ post-injection in 

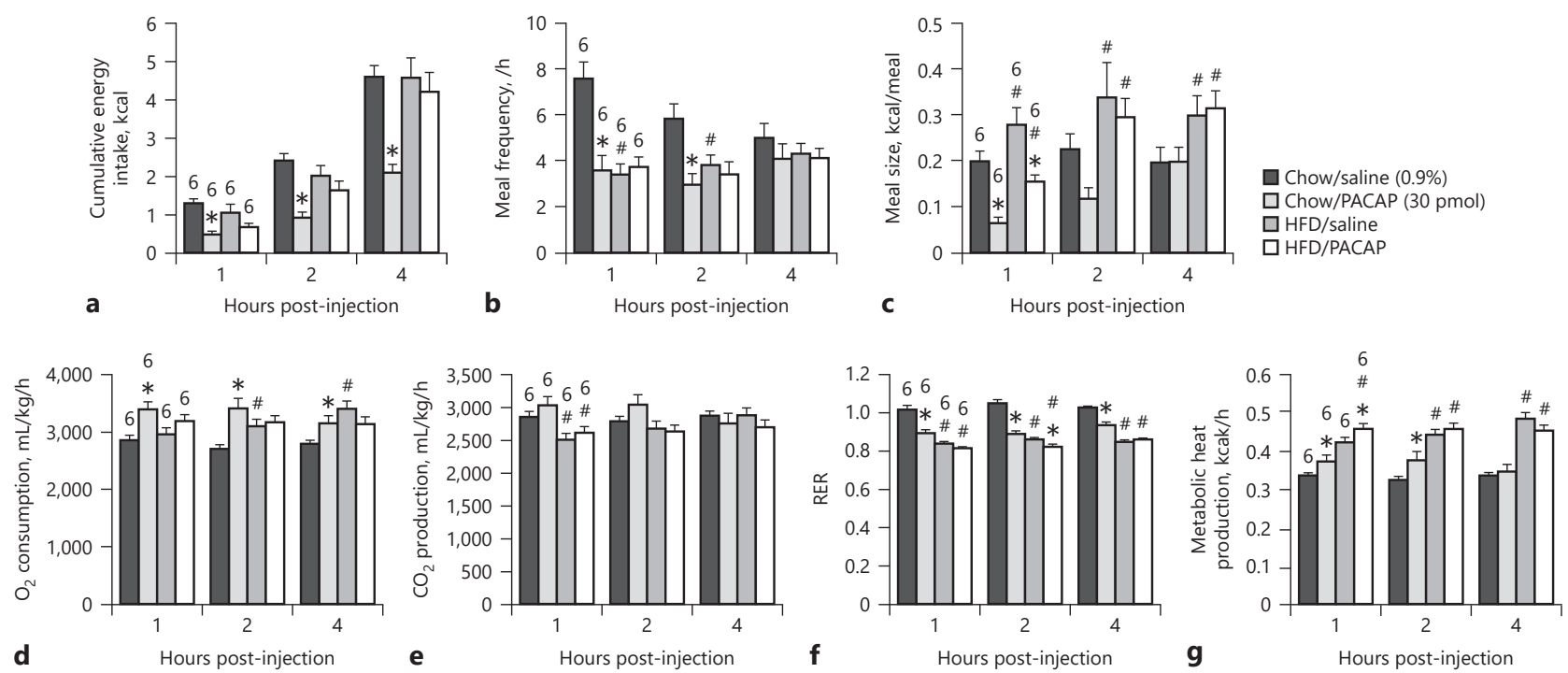

Fig. 10. Direct injection of PACAP into the ARC significantly decreases energy intake and increases energy expenditure in a dietsensitive manner. PACAP (30 pmol; chow-fed) significantly decreases cumulative energy intake (a) in chow-fed wild-type male mice compared to saline-treated controls $(0.2 \mu \mathrm{L})$, which is associated with decreased meal frequency (b) and meal size (c). Metabolically, PACAP increased $\mathrm{O}_{2}$ consumption (d) and is without effect on $\mathrm{CO}_{2}$ production (e), which effectively decreases RER (f). g As with $\mathrm{O}_{2}$ consumption, PACAP also increases metabolic heat

comparison to the saline control group (Fig. 10a; multifactorial ANOVA/LSD: $F_{\text {hour }}=103.72, \mathrm{df}=2, p<0.0001, F_{\mathrm{PA}}$ $\mathrm{CAP}=32.01, \mathrm{df}=1, p<0.0001, F_{\text {diet }}=5.06, \mathrm{df}=1, p<0.03$, $F_{\text {interaction }}=12.29, \mathrm{df}=1, p<0.0005$; one-way ANOVA/ LSD: $F_{\text {ratio }}$ groups $\left.=25.94, \mathrm{df}=11, p<0.0001\right)$. This effect was associated with decreases in meal frequency and size (Fig. 10b; multifactorial ANOVA/LSD: $F_{\text {hour }}=1.15, \mathrm{df}=2$, $p<0.32, F_{\mathrm{PACAP}}=17.69, \mathrm{df}=1, p<0.0001, F_{\text {diet }}=43.82$, $\mathrm{df}=1, p<0.001, F_{\text {interaction }}=15.80, \mathrm{df}=1, p<0.0001$; oneway ANOVA/LSD: $F_{\text {ratio }}$ groups $=5.83, \mathrm{df}=11, p<0.0001$; Fig. 10c; multifactorial ANOVA/LSD: $F_{\mathrm{PACAP}}=9.24 ; \mathrm{df}=$ $1, p<0.003, F_{\text {diet }}=20.99, \mathrm{df}=1, p<0.0001, F_{\text {hour }}=3.94$, $\mathrm{df}=2, p<0.03, F_{\text {interaction }}=3.09, \mathrm{df}=1, p<0.05$; one-way ANOVA/LSD: $F_{\text {ratio }}$ groups $\left.=3.55 ; \mathrm{df}=11, p<0.0001\right)$. Regarding energy expenditure, PACAP significantly increased $\mathrm{O}_{2}$ consumption at $1 \mathrm{~h}$ post-injection (Fig. 10d; multifactorial ANOVA/LSD: $F_{\mathrm{PACAP}}=17.97 \mathrm{df}=1, p<$ $0.0001, F_{\text {diet }}=2.96, \mathrm{df}=1, p<0.09, F_{\text {hour }}=0.06, \mathrm{df}=2, p<$ $0.95, F_{\text {interaction }}=16.48, \mathrm{df}=1, p<0.0001$; one-way ANOVA/LSD: $F_{\text {ratio }}$ groups $\left.=4.76, \mathrm{df}=11, p<0.0001\right)$ and produced a slight albeit statistically insignificant increase in $\mathrm{CO}_{2}$ production (Fig. 10e; multifactorial ANOVA/LSD: production. The effects of PACAP on energy intake, meal pattern, and energy expenditure are appreciably attenuated in obese, insulin-resistant animals. Bars represent means and lines 1 SEM of the cumulative food intake, meal frequency, meal size, $\mathrm{O}_{2}$ consumption, $\mathrm{CO}_{2}$ production, $\mathrm{RER}$, and metabolic heat production, seen in chow- or HFD-fed male mice injected with either PACAP or its saline vehicle. ${ }^{*} p<0.05$ relative to saline vehicle, repeated-measures, multifactorial ANOVA/LSD; ${ }^{*} p<0.05$ relative to chow-fed controls, repeated measures, multifactorial ANOVA/LSD.
$F_{\text {hour }}=0.28, \mathrm{df}=2, p<0.76, F_{\mathrm{PACAP}}=0.23, \mathrm{df}=1, p<0.64$, $F_{\text {diet }}=13.52, \mathrm{df}=1, p<0.0003, F_{\text {interaction }}=3.23, \mathrm{df}=2, p<$ 0.05 ; one-way ANOVA/LSD: $F_{\text {ratio }}$ groups $=2.42, \mathrm{df}=11$, $p<0.007)$. These effects of PACAP were accompanied by decreases in RER (Fig. 10f; multifactorial ANOVA/LSD: $F_{\text {hour }}=4.65, \mathrm{df}=2, p<0.02, F_{\mathrm{PACAP}}=102.53, \mathrm{df}=1, p<$ $0.0001, F_{\text {diet }}=333.93, \mathrm{df}=1, p<0.0001, F_{\text {interaction }}=62.05$, $\mathrm{df}=1, p<0.0001$; one-way ANOVA/LSD: $F_{\text {ratio }}$ groups $=$ 53.08, $\mathrm{df}=11, p<0.0001)$ and increases in metabolic heat production (Fig. 10g; multifactorial ANOVA/LSD: $F_{\text {hour }}=$ $0.37, \mathrm{df}=2, p<0.7, F_{\mathrm{PACAP}}=7.53, \mathrm{df}=1, p<0.007, F_{\text {Diet }}=$ 203.17, $\mathrm{df}=1, p<0.0001, F_{\text {interaction }}=4.29, \mathrm{df}=2, p<0.0146$; one-way ANOVA/LSD: $F_{\text {ratio }}$ groups $=22.66, \mathrm{df}=11, p<$ 0.0001). Importantly, the effect of intra-ARC PACAP on energy intake, meal pattern and energy expenditure seen in obese, HFD-fed males was either completely abolished or, at the very least, appreciably attenuated. Thus, the comprised excitatory transmission occurring at anorexigenic VMN PACAP/ARC POMC synapses under conditions of diet-induced obesity/insulin resistance hampers the ability of PACAP to decrease energy intake and increase energy expenditure. 

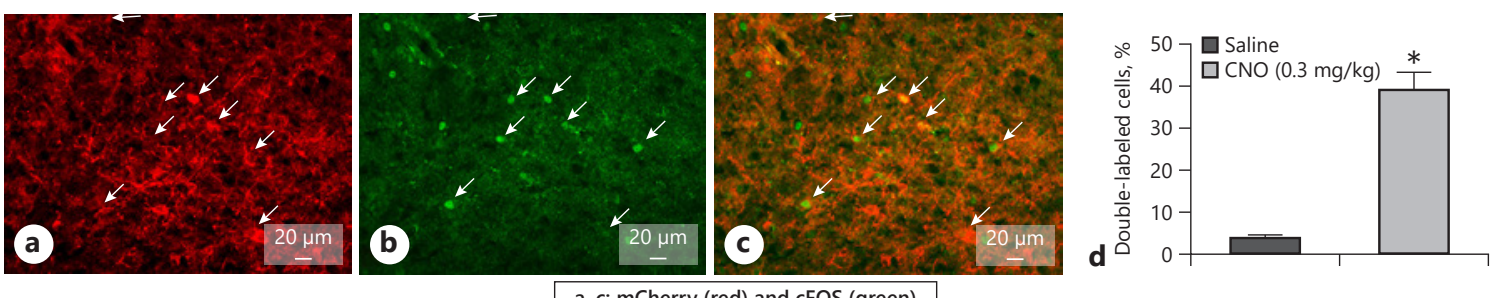

a-c: mCherry (red) and cFOS (green)

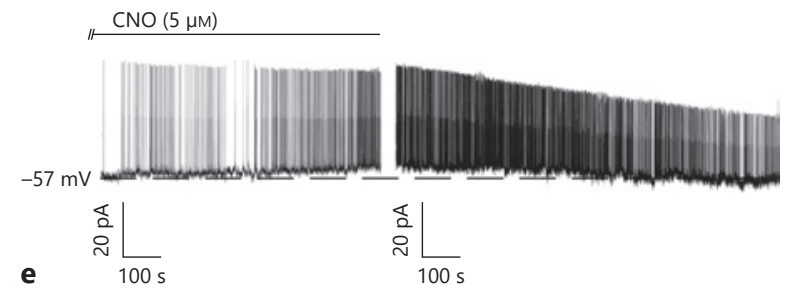

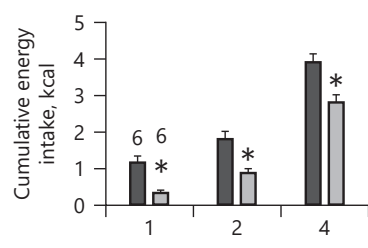

g

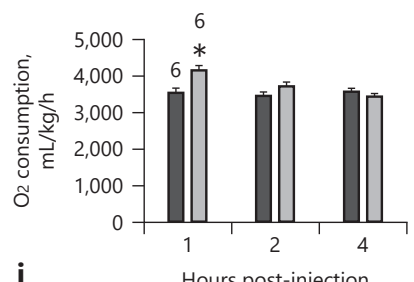

j

Hours post-injection

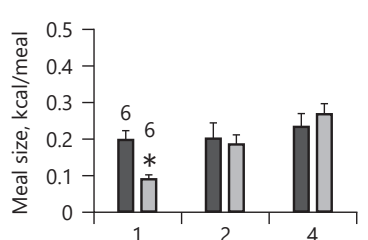

h

Hours post-injection

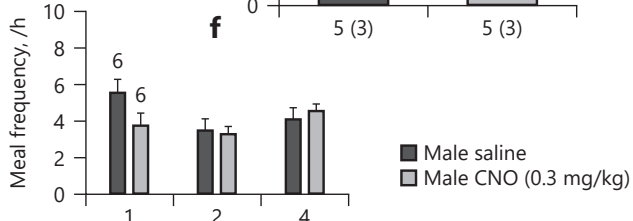

i

Hours post-injection

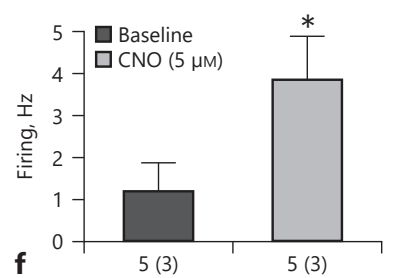

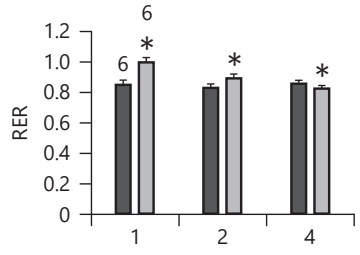

I

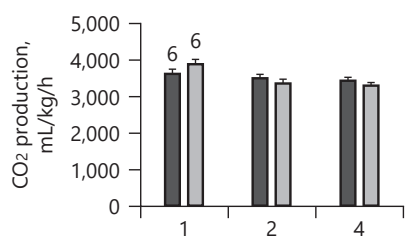

Hours post-injection

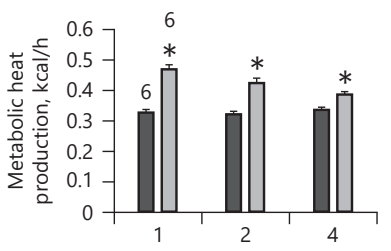

m

Hours post-injection
Fig. 11. Chemogenetic stimulation of VMN PACAP neurons increases c-Fos expression and decreases food intake and increases energy expenditure in male PACAP-cre mice. The color photomicrographs depict mCherry and c-Fos immunoreactivity, as well as the respective composite overlay, in sections taken from CNOtreated animals $(0.3 \mathrm{mg} / \mathrm{kg}$ s.c.; $\mathbf{a}-\mathbf{c})$. d Composite bar graph showing the dramatic increase in c-Fos expression in VMN PACAP neurons. e, $\mathbf{f}$ In vitro chemogenetic stimulation of VMN PACAP neurons with CNO $(5 \mu \mathrm{M})$ reversibly depolarizes them and increases their firing rate. The break in the traces represents the time necessary to conduct the second ramp I/V.g CNO reduces cumulative food intake, and this correlates with a time-dependent de- crease in meal size (h) but not frequency (i). CNO treatment also increases $\mathrm{O}_{2}$ consumption $(\mathbf{j})$ but not $\mathrm{CO}_{2}$ production $(\mathbf{k})$, which consequentially decreases RER (I). $\mathbf{m}$ Pronounced elevations in metabolic heat production are also seen. Bars represent means and lines 1 SEM of the cumulative food intake, meal frequency, meal size, $\mathrm{O}_{2}$ consumption, $\mathrm{CO}_{2}$ production, $\mathrm{RER}$, and metabolic heat production, seen in male mice injected with either $\mathrm{CNO}$ or its saline vehicle. f Numbers centered below the data bars denote the number of recorded cells, whereas those parenthetically enclosed represent the number of animals. ${ }^{*} p<0.05$ relative to saline vehicle or baseline; Mann-Whitney U test (d), paired $t$ test $(\mathbf{f})$, repeated-measures, multifactorial ANOVA/LSD (h-m).
Chemogenetic Stimulation of VMN PACAP Neurons Significantly Decreases Food Intake and Increases Energy Expenditure

Given how intra-ARC administration of exogenous PACAP prominently decreased energy intake and increased energy expenditure, we now wanted to ascertain if these effects could be replicated by selective chemoge- netic activation of VMN PACAP neurons. Male PACAPCre mice were bilaterally injected with a $\mathrm{G}_{\mathrm{q}}$-coupled, M3DREADD viral vector into the dorsomedial VMN. Chemoactivation of VMN PACAP neurons with CNO $(0.3$ $\mathrm{mg} / \mathrm{kg}$ s.c.) elicited a significant increase in c-Fos expression within these cells (Fig. 11a-d; Mann-Whitney U test: $\mathrm{W}=0, p<0.00007)$. In recordings from VMN PACAP
60

Neuroendocrinology 2021;111:45-69 DOI: $10.1159 / 000506367$
Chang/Hernandez/Gastelum/Guadagno/ Perez/Wagner 


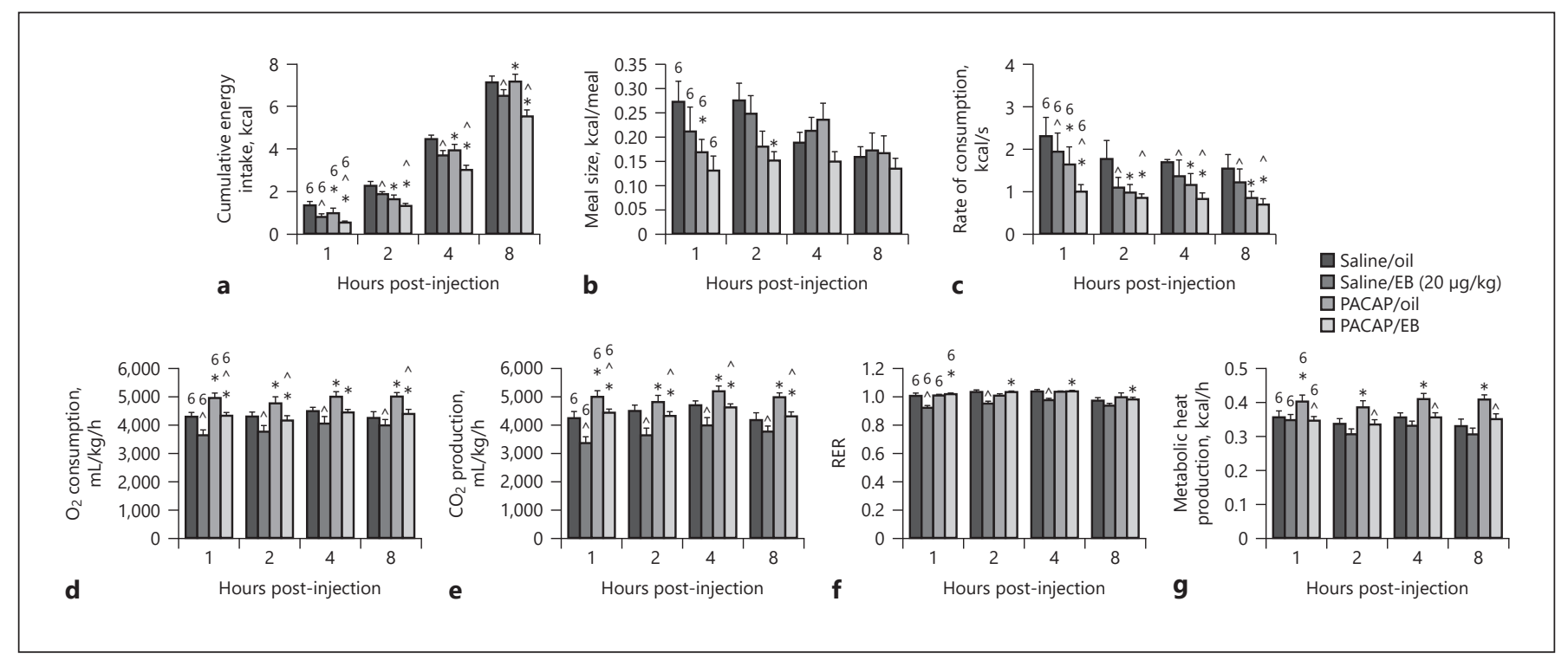

Fig. 12. $\mathrm{E}_{2}$ accentuates the decrease in energy intake caused by PACAP administered directly into the ARC. a PACAP (30 pmol) significantly decreased cumulative energy intake in chow-fed, OVX wild-type females, which was intensified by EB treatment $(20 \mu \mathrm{g} /$ $\mathrm{kg}$ s.c.). It also decreases meal size (b) and the rate of consumption (c), the latter of which was further enhanced with EB treatment. In addition, $\mathrm{PACAP}$ increased $\mathrm{O}_{2}$ consumption $(\mathbf{d})$ and $\mathrm{CO}_{2}$ production (e) in both oil- and EB-treated animals, as well as RER in EBtreated animals (f) and metabolic heat production in oil-treated animals $(\mathbf{g})$. With the exception of RER, EB did not further elevate PACAP-induced increases in these indices of energy expenditure. Bars represent means and lines 1 SEM of the cumulative food intake, meal size, rate of consumption, $\mathrm{O}_{2}$ consumption, $\mathrm{CO}_{2}$ production, RER, and metabolic heat production seen in OVX oil- or EB-treated female mice injected with either PACAP or its saline vehicle. ${ }^{*} p<0.05$ relative to saline vehicle, repeated-measures, multifactorial ANOVA/LSD; $\wedge p<0.05$ relative to sesame oil vehicle, repeated-measures, multifactorial ANOVA/LSD. neurons, $\mathrm{CNO}(5 \mu \mathrm{M})$ robustly depolarized and increased their firing rate $\sim 3 \times$ that of baseline (Fig. 11e, f; paired $t$ test: $t=-4.7001, p<0.02)$. Moreover, $\mathrm{CNO}$ decreased $\mathrm{cu}-$ mulative food intake that was apparent from 1 to $4 \mathrm{~h}$ post injection (Fig. 11g; multifactorial ANOVA/LSD: $F_{\text {hour }}=$ $118.85, \mathrm{df}=2, p<0.0001, F_{\mathrm{CNO}}=43.83, \mathrm{df}=1, p<0.0001$, $\left.F_{\text {interaction }}=0.32, \mathrm{df}=2, p<0.73\right)$ as compared to vehicletreated or CNO-treated, sham-injected controls (Table 1; multifactorial ANOVA/LSD: $F_{\text {hour }}=71.22, \mathrm{df}=2, p<$ $0.00001, F_{\mathrm{CNO}}=21.38, \mathrm{df}=3, p<0.00001, F_{\text {interaction }}=$ 0.34 , $\mathrm{df}=6, p<0.92)$. This was associated with a timedependent decrease in meal size but not frequency (Fig. 11h; multifactorial ANOVA/LSD: $F_{\text {hour }}=2.43 \mathrm{df}=$ $2, p<0.1), F_{\mathrm{CNO}}=1.10, \mathrm{df}=1, p<0.2968, F_{\text {interaction }}=1.91$, $\mathrm{df}=2, p<0.16$; Fig. 11i; multifactorial ANOVA/LSD: $F_{\text {hour }}=5.88, \mathrm{df}=2, p<0.005, F_{\mathrm{CNO}}=2.66, \mathrm{df}=1, p<0.11$, $F_{\text {interaction }}=3.56, \mathrm{df}=2, p<0.04$; one-way ANOVA/LSD: $F_{\text {ratio }}$ groups $\left.=4.38, \mathrm{df}=5, p<0.002\right)$. CNO treatment also increased $\mathrm{O}_{2}$ consumption, decreased RER, and increased metabolic heat production (Fig. 11j; multifactorial ANOVA/LSD: $F_{\text {hour }}=6.17, \mathrm{df}=2, p<0.004, F_{\mathrm{CNO}}=6.89, \mathrm{df}=$ $1, p<0.02, F_{\text {interaction }}=7.03, \mathrm{df}=2, p<0.002$; one-way ANOVA/LSD: $F_{\text {ratio }}$ groups $=6.66, \mathrm{df}=5, p<0.0001$;
Table 1. CNO treatment suppresses cumulative energy intake in $\mathrm{G}_{\mathrm{q}}$-M3-DREADD- but not sham-injected PACAP-cre mice

\begin{tabular}{|c|c|c|c|}
\hline \multirow[t]{2}{*}{ Treatment } & \multicolumn{3}{|c|}{ Cumulative intake, kcal } \\
\hline & hour 1 & hour 2 & hour 4 \\
\hline Saline/G $\mathrm{G}_{\mathrm{q}}-\mathrm{M} 3-\mathrm{DREADD}$ & $1.17 \pm 0.18$ & $1.82 \pm 0.21$ & $3.93 \pm 0.22$ \\
\hline $\mathrm{CNO} /$ sham-injected controls & $0.97 \pm 0.17$ & $1.83 \pm 0.27$ & $3.61 \pm 0.32$ \\
\hline $\mathrm{CNO} / \mathrm{G}_{\mathrm{q}}-\mathrm{M} 3$-DREADD & $0.34 \pm 0.08^{*}$ & $0.89 \pm 0.12^{*}$ & $2.81 \pm 0.21^{*}$ \\
\hline
\end{tabular}

Values represent mean \pm 1 SEM. ${ }^{*} p<0.05$ relative to saline vehicletreated animals.

Fig. 11k; multifactorial ANOVA/LSD: $F_{\text {hour }}=3.82, \mathrm{df}=2$, $p<0.03, F_{\mathrm{CNO}}=2.23, \mathrm{df}=1, p<0.14, F_{\text {interaction }}=3.36$, $\mathrm{df}=2, p<0.04$; one-way ANOVA/LSD: $F_{\text {ratio }}$ groups $=$ 3.32, $\mathrm{df}=5, p<0.009$; Fig. 11l; multifactorial ANOVA/ LSD: $F_{\text {hour }}=5.18, \mathrm{df}=2, p<0.008, F_{\mathrm{CNO}}=100.64, \mathrm{df}=1$, $p<0.0001, F_{\text {interaction }}=7.20, \mathrm{df}=2, p<0.002$; one-way ANOVA/LSD: $F_{\text {ratio }}$ groups $=25.08, \mathrm{df}=5, p<0.0001$; Fig. $11 \mathrm{~m}$; multifactorial ANOVA/LSD: $F_{\text {hour }}=5.18, \mathrm{df}=$ $2, p<0.008, F_{\mathrm{CNO}}=100.64, \mathrm{df}=1, p<0.0001, F_{\text {interaction }}=$ $7.20, \mathrm{df}=2, p<0.002$; one-way ANOVA/LSD: $F_{\text {ratio }}$ 

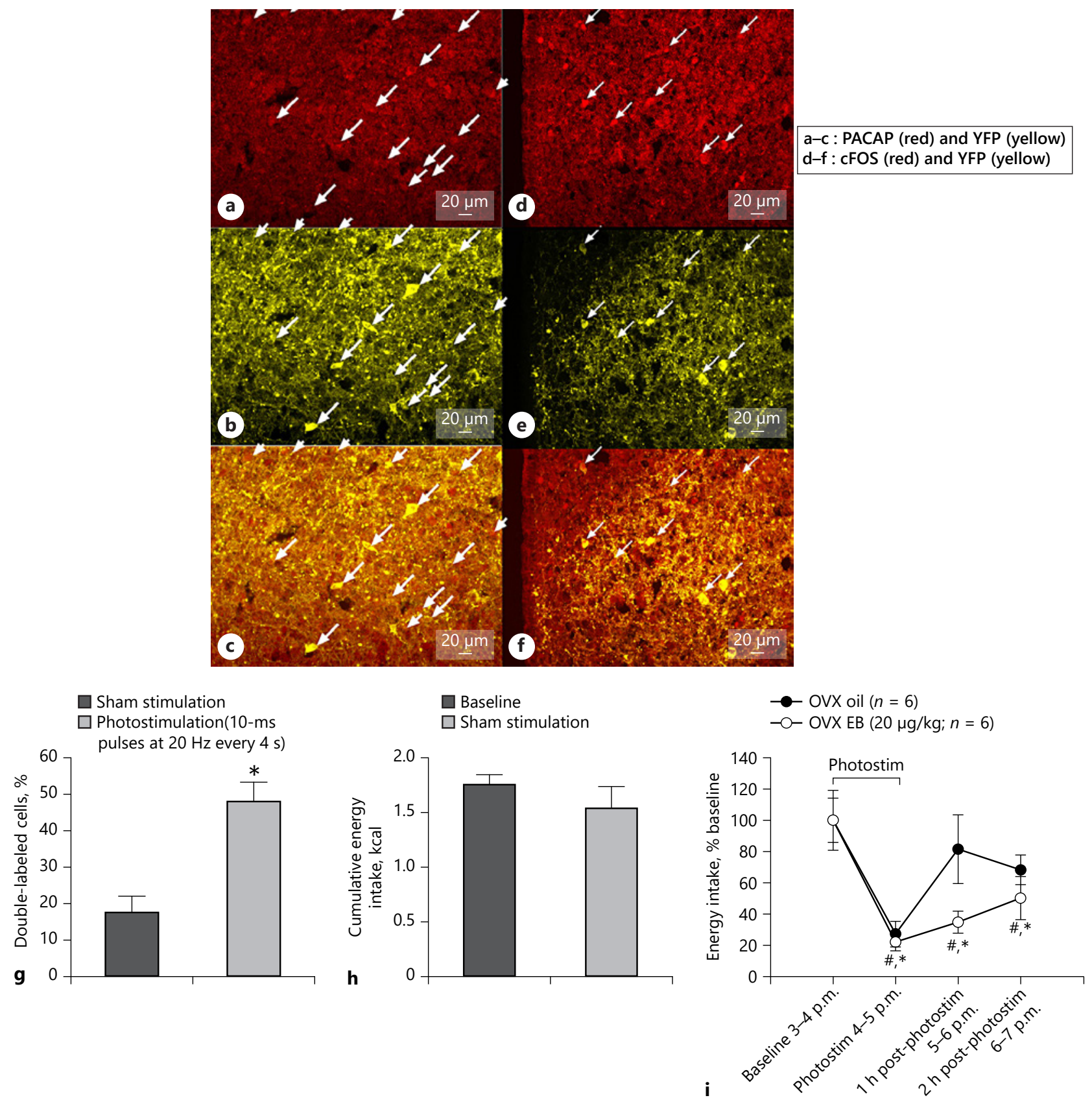

Fig. 13. Optogenetic stimulation of VMN PACAP neurons increases c-Fos expression and decreases energy intake, the latter of which is potentiated by EB. a-c Color photomicrographs illustrating PACAP immunoreactivity (top), eYFP labeling (middle), and the composite overlay (bottom). d-f The remaining photomicrographs reveal c-Fos immunoreactivity (top), eYFP labeling (middle), and the composite overlay (bottom) in sections from photostimulated OVX females. g-i Bar graphs showing the photostim- ulation-induced increase in c-Fos expression within VMN PACAP neurons and the corresponding reduction in energy intake that is augmented by EB. Bar graphs represent means and line 1 SEM. $* p<0.05$ relative to sham stimulation (g), Mann-Whitney U test; $* p<0.05$ relative to oil vehicle (i), rank-transformed, multifactorial ANOVA/LSD; ${ }^{*} p<0.05$ relative to prephotostimulation baseline (i), rank-transformed, multifactorial ANOVA/LSD. 
Fig. 14. Schematic illustrating the PAC1 receptor signaling occurring at VMN PACAP/ARC POMC synapses. PACAP activates a somatodendritic, $G_{q}$-coupled PAC1 receptor that activates TRPC5 channels in POMC neurons within the ARC via PI3K, PLC, and PKC signaling. This leads to membrane depolarization and an increase in firing. This PACAP-induced increase in excitability is accentuated by $\mathrm{E}_{2}$ acting at ER $\alpha$ and the $\mathrm{G}_{\mathrm{q}}$-coupled mER and attenuated by HFD-induced obesity/insulin resistance.

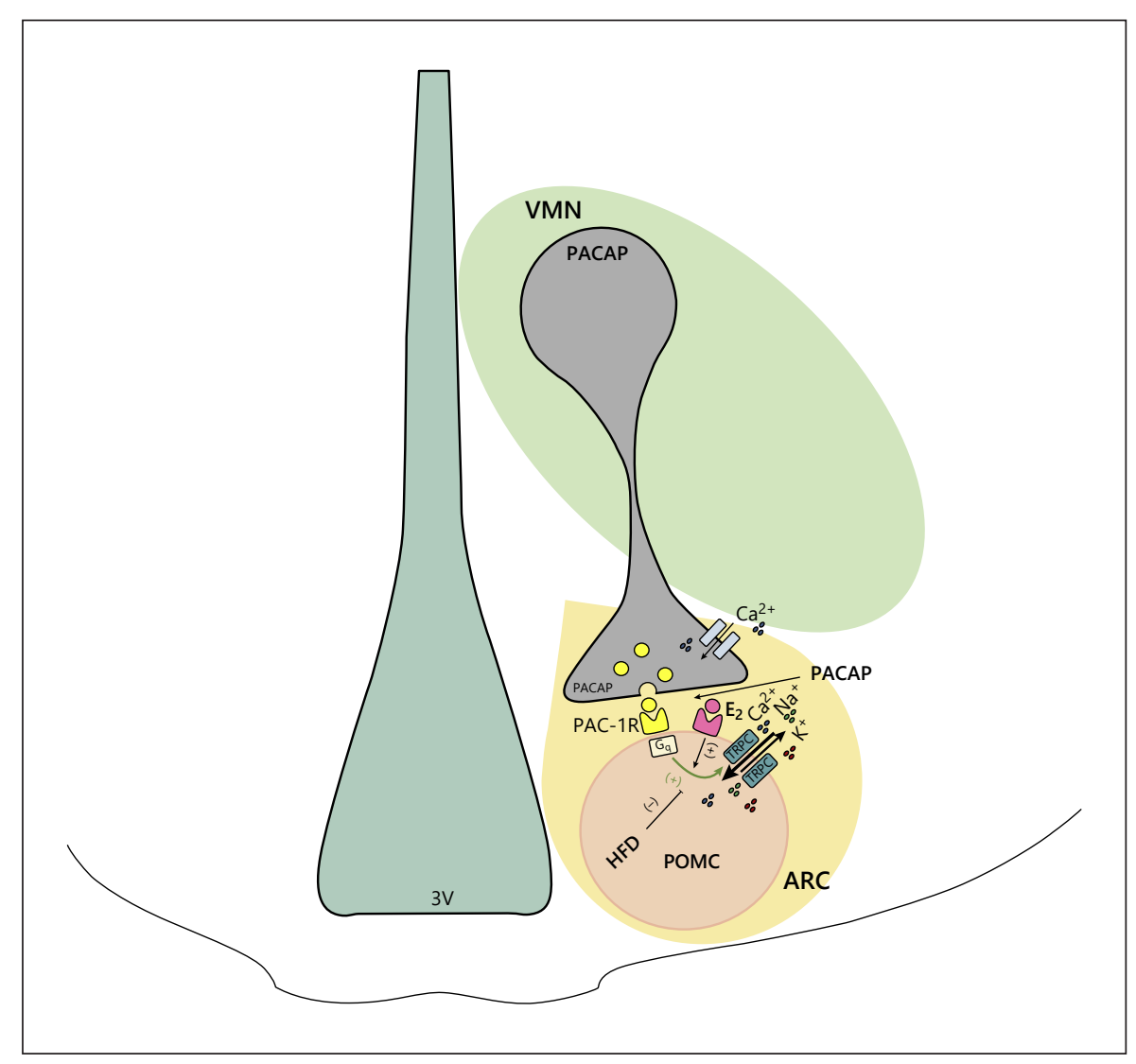

groups $=81.43, \mathrm{df}=1, p<0.0001)$. Thus, as with intraARC injection of exogenous PACAP, chemogenetic activation of VMN PACAP neurons exerts meaningful and physiologically relevant decreases in energy intake accompanied by increases in energy expenditure in males.

$\mathrm{E}_{2}$ Amplifies the Decrease in Energy Intake Caused by Intra-ARC PACAP and Optogenetic Stimulation of VMN PACAP Neurons

Given the estrogenic potentiation of the $\mathrm{PAC} 1$ receptor-mediated activation of TRPC5 channels in POMC neurons, we set out to determine if $\mathrm{E}_{2}$ could similarly augment the alterations in energy balance caused by intraARC PACAP. As shown in Figure 12a, significant main effects were seen with both EB and PACAP regarding energy intake; thus, EB per se decreased energy intake in chow-fed, OVX wild-type females, and intensified the reduction caused by PACAP (multifactorial ANOVA/LSD: $F_{\mathrm{EB}}=38.39, \mathrm{df}=1, p<0.0001, F_{\mathrm{PACAP}}=18.69, \mathrm{df}=1, p<$ $0.0001, F_{\text {hour }}=495.04, \mathrm{df}=3, p<0.0001, F_{\text {interaction }}=1.24$, $\mathrm{df}=1, p<0.27)$. This could not be accounted for by further decreases in meal size, as PACAP reduced meal size to equivalent degrees (albeit at different time points) in oil- and EB-treated females (Fig. 12b; multifactorial ANOVA/LSD: $F_{\mathrm{EB}}=0.85, \mathrm{df}=1, p<0.36, F_{\mathrm{PACAP}}=12.05$, $\mathrm{df}=1, p<0.0006, F_{\text {hour }}=3.05, \mathrm{df}=3, p<0.03$, $F_{\text {interaction }}=3.14, \mathrm{df}=1, p<0.03$; one-way ANOVA/LSD: $\left.F_{\text {between groups }}=2.48, \mathrm{df}=15, p<0.002\right)$. However, significant main effects of both EB and PACAP were again observed for rate of consumption; meaning that EB per se decreased the rate of consumption, and potentiated the reduction caused by PACAP (Fig. 12c; multifactorial ANOVA/LSD: $F_{\mathrm{EB}}=6.75, \mathrm{df}=1, p<0.01, F_{\mathrm{PACAP}}=12.65$, $\mathrm{df}=1, p<0.0004, F_{\text {hour }}=2.84$, df $=3, p<0.04$, $\left.F_{\text {interaction }}=0.75, \mathrm{df}=1, p<0.39\right)$. This indicates that the augmented anorexigenic effect of PACAP in EB-treated can be attributed, at least in part, to a further reduction in the rate of consumption. For energy expenditure, there were also significant main effects of EB and PACAP on $\mathrm{O}_{2}$ consumption and $\mathrm{CO}_{2}$ production. $\mathrm{EB}$ per se decreased $\mathrm{O}_{2}$ consumption and $\mathrm{CO}_{2}$ production, whereas PACAP increased these parameters in both oil- and EBtreated animals (Fig. 12d; multifactorial ANOVA/LSD: $F_{\mathrm{EB}}=36.82, \mathrm{df}=1, p<0.0001, F_{\mathrm{PACAP}}=36.87, \mathrm{df}=1, p<$ 
$0.0001, F_{\text {hour }}=1.60, \mathrm{df}=3, p<0.2, F_{\text {interaction }}=0.55, \mathrm{df}=$ $1, p<0.46$; Fig. 12e; multifactorial ANOVA/LSD: $F_{\mathrm{EB}}=$ $42.65, \mathrm{df}=1, p<0.0001, F_{\mathrm{PACAP}}=44.56, \mathrm{df}=1, p<0.0001$, $F_{\text {hour }}=2.89, \mathrm{df}=3, p<0.04, F_{\text {interaction }}=0.46, \mathrm{df}=1, p<$ $0.5)$. This functionally translated into EB per se decreasing RER, and PACAP increasing RER in EB-treated animals (Fig. 12f; multifactorial ANOVA/LSD: $F_{\mathrm{EB}}=20.62$, $\mathrm{df}=1, p<0.0001, F_{\mathrm{PACAP}}=27.24, \mathrm{df}=1, p<0.0001$, $F_{\text {hour }}=10.51, \mathrm{df}=3, p<0.0001, F_{\text {interaction }}=30.00, \mathrm{df}=1$, $p<0.0001$; one-way ANOVA/LSD: $F_{\text {between groups }}=7.74$, $\mathrm{df}=15, p<0.0001)$. Lastly, PACAP increased metabolic heat production, which interestingly was reduced in EBtreated animals (Fig. 12g; multifactorial ANOVA/LSD: $F_{\mathrm{EB}}=22.53, \mathrm{df}=1, p<0.0001, F_{\mathrm{PACAP}}=25.69, \mathrm{df}=1, p<$ $0.0001, F_{\text {hour }}=1.96, \mathrm{df}=3, p<0.13, F_{\text {interaction }}=4.22, \mathrm{df}=$ $1, p<0.05$; one-way ANOVA/LSD: $F_{\text {between groups }}=3.97$, $\mathrm{df}=15, p<0.0001)$. Selective optogenetic stimulation of VMN PACAP neurons (Fig. 13a-c) in OVX females elevated c-fos expression within them (Fig. 13d-g; MannWhitney U test: $\mathrm{W}=8.5, p<0.02)$ and markedly reduced energy intake, the latter of which was not observed in sham-stimulated animals (Fig. 13h; Student's $t$ test: $t=1.03$, $p<0.32$ ) and potentiated in EB-treated animals (Fig. 13i; rank-transformed multifactorial ANOVA/LSD: $F_{\mathrm{EB}}=$ $4.89, \mathrm{df}=1, p<0.04, F_{\text {hour }}=11.59, \mathrm{df}=3, p<0.0001$, $\left.F_{\text {interaction }}=1.64, \mathrm{df}=1, p<0.2\right)$. These data indicate that the $\mathrm{E}_{2}$-induced potentiation of $\mathrm{PAC} 1$ receptor-mediated activation of TRPC5 channels in POMC neurons heightens the suppressant effect of PACAP on energy intake but not the increase in energy expenditure.

\section{Discussion}

The results generated from this project demonstrate that PACAP regulates energy homeostasis in a sex- and diet-dependent manner. These findings are based on the following observations: (1) PACAP elicits an inward current in ARC POMC neurons that is virtually abolished by PAC1R blockade and TRPC5 channel inhibition; (2) this inward current is significantly attenuated by inhibition of PLC, PI3K, and PKC but not PKA: (3) the PACAP-induced inward current is associated with a membrane depolarization and a resultant increase in firing, which is further enhanced by $\mathrm{E}_{2}$; (4) the inward current caused by exogenous PACAP is recapitulated by photo-stimulation of VMN PACAP neurons, which again is further augmented by $\mathrm{E}_{2}$ acting at $\mathrm{G}_{\mathrm{q}}$-coupled $\mathrm{mERs}$; (5) the PACAPinduced excitation of ARC POMC neurons, suppression of energy intake and increase in energy expenditure are markedly diminished by long-term HFD exposure in males; (6) in vivo chemogenetic stimulation of VMN PACAP neurons likewise suppresses appetite and increases energy expenditure; and (7) EB further accentuates the PACAP-induced decrease in energy intake (Fig. 14).

We have demonstrated that prolonged excitatory neurotransmission occurring at VMN PACAP/ARC POMC synapses arises from the activation of the $\mathrm{PAC} 1$ receptor and TRPC5 channels. It is observed in POMC neurons from both mice and guinea pigs, indicating that the response is conserved across species. This is consistent with the role of TRPC channels in the PACAP-induced increase in the excitability of guinea pig cardiac neurons [40]. This finding also aligns with other examples of TRPC5 channel-induced excitation of POMC neurons resulting from activation of insulin, leptin and serotonin receptors [17, 37, 41, 42]. While early investigations into the effects of various insulin formulations on the excitability of POMC neurons reported an inhibition caused by the activation of $\mathrm{K}_{\mathrm{ATP}}$ channels $[43,44]$, it has more recently been demonstrated that bovine, guinea pig, and human recombinant insulin depolarize and thereby increase the firing rate of POMC neurons via the activation of TRPC 5 channels $[17,45]$. This latter finding might explain the synergistic effects of insulin and leptin on adipose tissue browning and metabolism regulated by POMC neurons [46], especially when one considers that the heterogeneous profile of excitatory and inhibitory responses to insulin is heavily influenced by the prevailing levels of protein phosphatase activity in POMC neurons $[47,48]$. The PAC1 receptor-mediated excitation we observed presently may be responsible for the reported anxiogenic effect of PACAP, as Iemolo et al. [49] found that it was abrogated by microinfusion of the MC4R receptor antagonist into the central nucleus of the amygdala. It also coincides with previous reports that PACAP increases POMC mRNA expression when administered directly into the mediobasal hypothalamus [2, 3, 12], and that blocking endogenous PACAP signaling with the PAC1 receptor antagonist PACAP6-38 markedly attenuates leptin-induced hypophagia and hyperthermia in vivo [11]. Our present results, coupled with earlier findings from other investigators, show that PACAP expression in the $\mathrm{VMN}$ is driven, at least in part, by the transcription factor SF-1 $[10,11]$. Given that leptin stimulates both SF-1/PACAP and POMC neurons' activation of TRPC5 channels, and presumably the excitatory neurotransmission at synapses formed between the two cell types $[5,17$, $36,50]$, this strongly indicates that these synapses are an integrative cornerstone within the hypothalamic energy
Chang/Hernandez/Gastelum/Guadagno/ Perez/Wagner 
balance circuitry. Moreover, VMN PACAP/ARC POMC synapses serve as a point of convergence for the regulatory actions of other regulators of POMC neurons, such as endocannabinoids as well as peptide hormones and transmitters like insulin and nociceptin/orphanin FQ $[38,39,51,52]$.

It is well established that PAC1R is a G protein-coupled receptor that can stimulate adenylate cyclase activity [5, 17]; however, Nishimoto et al. [15] found that the PA$\mathrm{CAP} / \mathrm{PAC1}$ system potentiated growth factor-induced proliferation of mouse cortical NPCs at E14.5 via $\mathrm{G}_{\mathrm{q}^{-}}$but not $\mathrm{G}_{\mathrm{s}}$-mediated PLC/IP3-dependent signaling pathway. In addition, physiological studies have demonstrated that PACAP acts on PAC1 receptor in mouse neural stem cells and the signal generated upon receptor activation is carried via $G_{\mathrm{q}}$ but not $\mathrm{G}_{\mathrm{s}}$ [53]. In the present study, we found that the PAC1 receptor-mediated activation of TRPC5 channels in POMC neurons is attributable to $\mathrm{G}_{\mathrm{q}}$-coupled stimulation of PI3K-PLC-PKC signal transduction. We utilized a PLC inhibitor, U73122, and saw that this led to a complete abolishment of PACAP-induced inward current in POMC neurons, whereas the inactive isomer was without effect on the PACAP-induced inward current. We also bath-applied inhibitors of both PI3K and PKC, and again saw that PACAP's effects were completely negated. These data are in keeping with the fact that in hippocampal CA1 neurons, PAC1 receptors couple to $G_{q}$, PLC and PKC to potentiate NMDA receptor-mediated currents, an effect that also requires increases in intracellular $\mathrm{Ca}^{2+}$ and activation of Src [54]. The activation of $\mathrm{PI} 3 \mathrm{~K}$ presently seen is consistent with the effects of PACAP in rat schwannoma cells, in which the peptide enhances the phosphorylation of Akt at Ser473 to augment myelin protein expression [55]. On the other hand, $\mathrm{G}_{\mathrm{s}}$ does not appear to be involved in the PAC1 receptor-mediated excitation of POMC neurons, as the PKA inhibitor KT5720 was without effect on the PACAP-induced inward current. This is incongruent with a previous report in hippocampal neurons, in which PACAP negatively modulates A-type $\mathrm{K}^{+}$currents through Kv4.2 channels via $G_{s}$ and a pathway involving PKA and ERK1/2 phosphorylation of these channels [56]. Thus, the current data clearly support the notion that PACAP works through a $\mathrm{PI} 3 \mathrm{~K} / \mathrm{PLC} / \mathrm{PKC}$ pathway to stimulate POMC neurons via TRPC5 channels upon PAC1 receptor activation, and we can assert that PACAP excites POMC neurons via $\mathrm{G}_{\mathrm{q}^{-}}$ mediated signaling.

Our present study also demonstrates that this postsynaptic effect of PACAP in POMC neurons is sexually differentiated; with females being more sensitive than males in the presence of $E_{2}$. This is consistent with the findings of Spence et al. [57], in which expression of the Adcyap1r1 gene, encoding the PAC1 receptor, is upregulated in the nucleus accumbens of females compared to males, and enhanced by ER $\alpha$-mediated transcription of the gene. Earlier studies showed that brain ADCYAP1 transcript levels vary across the rat estrous cycle; with the greatest change occurring during proestrus [58], a period characterized by peak $\mathrm{E}_{2}$ levels. In sexually mature females, $\mathrm{PAC1}$ receptor expression and its associated functions are regulated in an estrogen-dependent manner, as longterm $\mathrm{E}_{2}$ treatment of OVX female rats via continuous release estrogen pellets has been shown to increase ADCYAP1R1 and ADCYAP1 transcript expression within the BNST [19]. The estrogenic potentiation of the PACAP/ $\mathrm{PAC1}$ receptor system aligns with our findings, as the PACAP-induced inward current and the associated depolarization and increase in firing in POMC neurons are potentiated in the presence of $\mathrm{E}_{2}$.

$E_{2}$ is known to exhibit anorexigenic effects, and in cycling women food intake is at its lowest when $\mathrm{E}_{2}$ levels are at their highest during the periovulatory phase of the cycle $[59,60]$. The present results demonstrate that $\mathrm{E}_{2}$ potentiates the anorexigenic effect of PACAP when administered directly into the ARC, which is due, at least in part, to enhanced $\mathrm{G}_{\mathrm{q}}$-mediated signaling in POMC neurons upon activation of the PAC1 receptor. This is in agreement with previous reports that $\mathrm{E}_{2}$ augments the excitatory effects of anorexigenic neurotransmitters and hormones such as serotonin and insulin on POMC neuronal activity $[37,61]$. This positive estrogenic modulation occurs via the activation of the $\mathrm{G}_{\mathrm{q}}$-coupled $\mathrm{mER}$ and $\mathrm{ER} \alpha$, and in parallel with the attenuation of orexigenic inputs that inhibit POMC neuronal activity. The manner in which estradiol rapidly diminishes $\mu$-opioid, $\mathrm{GABA}_{B}$, $\mathrm{CB} 1$, and nociceptin opioid receptor-induced inhibition of POMC neurons is due to signaling through two parallel pathways: one involving PKA and PKC elicited following activation of the $\mathrm{G}_{\mathrm{q}}$-coupled mER [33, 62-64], and another pathway involving PI3K and neuronal nitric oxide synthase elicited following activation of $\operatorname{ERa}[33,50$, 65]. Thus, $E_{2}$ regulates energy homeostasis, at least in part, through augmentation of anorexigenic signaling concomitant with a dampening of orexigenic signaling in POMC neurons. The present results uncover the important contribution of PACAP, and how $\mathrm{E}_{2}$ potentiates excitatory PACAPergic tone at anorexigenic VMN PACAP/ARC POMC synapses via membrane-initiated signaling to further enhance PACAP activation of POMC neurons. This is accomplished by increases in PI3K, PLC 
and PKC signaling, and the subsequent activation of TRPC5 channels. On the other hand, our results indicate that $\mathrm{E}_{2}$ did not potentiate the metabolic effects of intraARC PACAP. VMN PACAP neurons project to and synapse with neuronal populations other than ARC POMC neurons (e.g., autonomic centers that may control sympathetic tone independently of energy intake $[1,6,14$, 66]). In addition, while on one hand $\mathrm{E}_{2}$ can increase energy expenditure via activation of ERa in the VMN [67], on the other it lowers core body temperature in both humans and rodents [68-70]. Thus, the manner in which $\mathrm{E}_{2}$ and PACAP converge to regulate the homeostatic control of energy balance is both interdependent and dissociable.

This present study also demonstrates that in obese, insulin-resistant males, the PACAP-induced activation of POMC neurons is diminished. Diet-induced obesity has long been associated with dysregulated neuroendocrine function within the hypothalamic energy balance circuitry. For instance, Fabelo et al. [38] previously found that obese males exhibit a more pronounced retrograde endocannabinoid-mediated inhibition of glutamatergic transmission at VMN SF-1/ARC POMC synapses, whereas in females this is due to a loss of functional excitatory synapses altogether. The changes caused by diet-induced obesity/insulin resistance are linked with disordered PI3K/Akt signaling in the VMN and ARC. For instance, the development of central insulin resistance in POMC neurons caused by diet-induced obesity is linked to reduced PI3K/Akt signaling in male but not female animals [37]. Conversely, diet-induced obesity promotes an insulin-dependent increase in PI3K signaling in the VMN [51]. Given that the PI3K/Akt and the energy sensor AMPK are associated with anorexigenic and orexigenic signaling, respectively $[41,71]$, these pathways work counter to one another in the hypothalamic control of energy homeostasis. Thus, the reduction in ARC PI3K/ Akt signaling seen with obesity/insulin resistance [37, 38], coupled with the testosterone-induced activation of AMPK in males [72, 73], helps explain how sex and diet converge to regulate anorexigenic signaling at PACAP/ POMC synapses. Since the diet-induced obesity/insulin resistance is linked to reduced PI3K/Akt signaling in males and PACAP's activational affects are mediated through PI3K, it should have come as no surprise when we saw that the diet-induced obesity/insulin resistance reversed PACAP's excitatory effects in male POMC neurons. Given the PACAP-induced postsynaptic activation on POMC neurons, it stands to reason that the marked diminution of this $\mathrm{G}_{\mathrm{q}}$-coupled metabotropic receptormediated response represents an important pathophysi- ological component of the dysregulated neurotransmission occurring with diet-induced obesity/insulin resistance in POMC neurons.

Our study found that direct administration of PACAP into the ARC as well as chemogenetic and optogenetic activation of VMN PACAP neurons both cause a significant decrease in energy intake as well as an increase in energy expenditure. While our data clearly show ChR2/ YFP-labeled PACAP fibers in close apposition to ARC POMC neurons, this does not constitute absolute proof that chemo/photostimulation of PACAP cell bodies in the VMN is stimulating the release of PACAP from terminals in the ARC. Nevertheless, these findings coincide with other studies that have found that not only ICV but also direct injections of PACAP into discrete hypothalamic nuclei causes a decrease in energy intake. Hurley et al. [74] found that microinjections of PACAP into the VMN mimicked the anorexigenic actions of AMPA injected into the same region. In addition, systemic administration of PACAP into wild type mice significantly decreased in a dose-dependent manner cumulative food intake and reduced various parameters of meal pattern such as meal size and rate of consumption; effects that were associated with reduced ghrelin secretion [75]. Injection of PACAP directly into the VMN or PVN reduced food intake, whereas intra-VMN but not intra-PVN increased both core body temperature and spontaneous locomotor activity along with a concurrent increase in UCP1 mRNA expression $[3,13]$. Our results identify another important and physiologically relevant hypothalamic region within which PACAP acts to not only suppress appetite but also to increase $\mathrm{O}_{2}$ consumption, $\mathrm{CO}_{2}$ production and metabolic heat production, as well as to decrease RER, in a sexually disparate and diet-sensitive manner. Reduction in body weight is consistently found following central PACAP injections; however, pair-feeding studies suggest that the body weight loss is not entirely due to decreased feeding, but also includes contributions from increased activity and metabolic rate $[11,13]$. Studies have shown that an increased RER is associated with increased carbohydrate metabolism and a decreased RER is associated with enhanced fat metabolism [76]. Presently, we observed that PACAP decreased RER in males, consistent with increased fat metabolism and increased UCP1 expression in BAT $[1,3]$. Conversely, PACAP increases RER in EB-treated OVX females, which is consistent with the comparatively greater PACAP-induced increase in $\mathrm{CO}_{2}$ consumption seen in EB-treated animals and suggestive of a sex difference in the manner in which PACAP regulates carbohydrate versus fat metabolism.
Chang/Hernandez/Gastelum/Guadagno/ Perez/Wagner 
In conclusion, the results generated during this project provide compelling support for the notion that PACAP regulates energy homeostasis, at least in part, via stimulation of POMC neurons. It does this by postsynaptically activating a $\mathrm{G}_{\mathrm{q}}$-coupled PAC1 receptor and TRPC5 channels in POMC neurons in a sex- and diet-dependent manner.

\section{Acknowledgements}

We thank Dr. Martin J. Kelly (Oregon Health and Science University) for his generous gift of STX.

\section{Statement of Ethics}

All procedures were approved by the Western University of Health Sciences' IACUC in accordance with institutional guidelines based on NIH standards.

\section{Disclosure Statement}

The authors have no conflicts of interest to declare.

\section{Funding Sources}

This study was supported by PHS Grant DA024314 and intramural funding from Western University of Health Sciences.

\section{Author Contributions}

R.C. and J.H. performed all stereotaxic and survival surgeries. R.C. and J.H. performed all electrophysiological recordings. R.C., J.H., L.P., and K.G. performed all metabolic studies. R.C., J.H. and E.J.W. performed data analysis for all electrophysiology and metabolic studies, while K.G. analyzed data for metabolic studies. R.C., J.H., and E.J.W. created all figures and performed all statistical analyses. R.C. and E.J.W. generated the manuscript, while R.C., J.H., L.P., and E.J.W. edited the final manuscript. E.J.W., R.C., and J.H. designed the experiments.

\section{References}

1 Rudecki AP, Gray SL. PACAP in the defense of energy homeostasis. Trends Endocrinol Metab. 2016 Sep;27(9):620-32.

2 Mounien L, Bizet P, Boutelet I, Gourcerol G, Fournier A, Vaudry H, et al. Pituitary adenylate cyclase-activating polypeptide directly modulates the activity of proopiomelanocortin neurons in the rat arcuate nucleus. Neuroscience. 2006 Nov;143(1):155-63.

3 Resch JM, Boisvert JP, Hourigan AE, Mueller CR, Yi SS, Choi S. Stimulation of the hypothalamic ventromedial nuclei by pituitary adenylate cyclase-activating polypeptide induces hypophagia and thermogenesis. Am J Physiol Regul Integr Comp Physiol. 2011 Dec; 301(6):R1625-34.

4 Sternson SM, Shepherd GMG, Friedman JM: Topographic mapping of VMH-arcuate nucleus microcirsuits and their reoganization by fasting. Nat Neurosci. 2005;8:1356-1363.

5 Dhillon H, Zigman JM, Ye C, Lee CE, McGovern RA, Tang V, et al. Leptin directly activates SF1 neurons in the VMH, and this action by leptin is required for normal body-weight homeostasis. Neuron. 2006 Jan;49(2):191-203.

6 Lindberg D, Chen P, Li C. Conditional viral tracing reveals that steroidogenic factor 1-positive neurons of the dorsomedial subdivision of the ventromedial hypothalamus project to autonomic centers of the hypothalamus and hindbrain. J Comp Neurol. 2013 Oct;521(14):3167-90.

7 Cardinal P, André C, Quarta C, Bellocchio L, Clark S, Elie M, et al. CB1 cannabinoid receptor in SF1-expressing neurons of the ventromedial hypothalamus determines metabolic responses to diet and leptin. Mol Metab. 2014 Aug;3(7):705-16
8 Chiappini F, Catalano KJ, Lee J, Peroni OD, Lynch J, Dhaneshwar AS, et al. Ventromedial hypothalamus-specific Ptpn1 deletion exacerbates diet-induced obesity in female mice. J Clin Invest. 2014 Sep;124(9):3781-92.

9 Majdic G, Young M, Gomez-Sanchez E, Anderson P, Szczepaniak LS, Dobbins RL, et al. Knockout mice lacking steroidogenic factor 1 are a novel genetic model of hypothalamic obesity. Endocrinology. 2002 Feb;143(2): 607-14.

10 Segal JP, Stallings NR, Lee CE, Zhao L, Socci $\mathrm{N}$, Viale A, et al. Use of laser-capture microdissection for the identification of marker genes for the ventromedial hypothalamic nucleus. J Neurosci. 2005 Apr;25(16):4181-8.

11 Hawke Z, Ivanov TR, Bechtold DA, Dhillon H, Lowell BB, Luckman SM. PACAP neurons in the hypothalamic ventromedial nucleus are targets of central leptin signaling. J Neurosci. 2009 Nov;29(47):14828-35.

12 Mounien L, Do Rego JC, Bizet P, Boutelet I, Gourcerol G, Fournier A, et al. Pituitary adenylate cyclase-activating polypeptide inhibits food intake in mice through activation of the hypothalamic melanocortin system. Neuropsychopharmacology. 2009 Jan;34(2):424-35.

13 Resch JM, Maunze B, Gerhardt AK, Magnuson SK, Phillips KA, Choi S. Intrahypothalamic pituitary adenylate cyclase-activating polypeptide regulates energy balance via sitespecific actions on feeding and metabolism. Am J Physiol Endocrinol Metab. 2013 Dec; 305(12):E1452-63.

14 Khodai T, Nunn N, Worth AA, Feetham CH, Belle MD, Piggins HD, et al. PACAP neurons in the ventromedial hypothalamic nucleus are glucose inhibited and their selective activa- tion induces hyperglycemia. Front Endocrinol. 2018;9:632.

15 Nishimoto M, Furuta A, Aoki S, Kudo Y, Miyakawa $\mathrm{H}$, Wada K. PACAP/PAC1 autocrine system promotes proliferation and astrogenesis in neural progenitor cells. Glia. 2007 Feb; 55(3):317-27.

16 Roy A, Derakhshan F, Wilson RJ. Stress peptide PACAP engages multiple signaling pathways within the carotid body to initiate excitatory responses in respiratory and sympathetic chemosensory afferents. Am J Physiol Regul Integr Comp Physiol. 2013 Jun; 304(12):R1070-84

17 Qiu J, Wagner EJ, Rønnekleiv OK, Kelly MJ. Insulin and leptin excite anorexigenic proopiomelanocortin neurones via activation of TRPC5 channels. J Neuroendocrinol. 2018 Feb;30(2):30.

18 Hammack SE, Cheung J, Rhodes KM, Schutz KC, Falls WA, Braas KM, et al. Chronic stress increases pituitary adenylate cyclase-activating peptide (PACAP) and brain-derived neurotrophic factor (BDNF) mRNA expression in the bed nucleus of the stria terminalis (BNST): roles for PACAP in anxiety-like behavior. Psychoneuroendocrinology. $2009 \mathrm{Jul}$; 34(6):833-43.

19 Ramikie TS, Ressler KJ. Stress-related disorders, pituitary adenylate cyclase-activating peptide (PACAP)ergic system, and sex differences. Dialogues Clin Neurosci. 2016 Dec; 18(4):403-13.

20 Mattis J, Tye KM, Ferenczi EA, Ramakrishnan C, O'Shea DJ, Prakash R, et al. Principles for applying optogenetic tools derived from direct comparative analysis of microbial opsins. Nat Methods. 2011 Dec;9(2):159-72. 
21 Qiu J, Bosch MA, Tobias SC, Grandy DK, Scanlan TS, Rønnekleiv OK, et al. Rapid signaling of estrogen in hypothalamic neurons involves a novel G-protein-coupled estrogen receptor that activates protein kinase C. J Neurosci. 2003 Oct;23(29):9529-40.

22 Qiu J, Nestor CC, Zhang C, Padilla SL, Palmiter RD, Kelly MJ, et al. High-frequency stimulation-induced peptide release synchronizes arcuate kisspeptin neurons and excites GnRH neurons. eLife. 2016 Aug;5:e16246.

23 Micevych PE, Elde RP. Neurons containing alpha-melanocyte stimulating hormone and beta-endorphin immunoreactivity in the cat hypothalamus. Peptides. 1982 Jul-Aug;3(4): 655-62.

24 Zheng H, Patterson LM, Berthoud HR. CART in the dorsal vagal complex: sources of immunoreactivity and effects on Fos expression and food intake. Brain Res. 2002 Dec;957(2):298310.

25 Woodley PK, Min Q, Li Y, Mulvey NF, Parkinson DB, Dun XP. Distinct VIP and PACAP functions in the distal nerve stump during peripheral nerve regeneration. Front $\mathrm{Neu}-$ rosci. 2019 Dec;13:1326.

26 El Hajj Chehadeh S, Dreumont N, Willekens J, Canabady-Rochelle L, Jeannesson E, Alberto JM, et al. Early methyl donor deficiency alters cAMP signaling pathway and neurosteroidogenesis in the cerebellum of female rat pups. Am J Physiol Endocrinol Metab. 2014 Dec;307(11):E1009-19.

27 Stancovski I, Gonen H, Orian A, Schwartz AL, Ciechanover A. Degradation of the proto-oncogene product c-Fos by the ubiquitin proteolytic system in vivo and in vitro: identification and characterization of the conjugating enzymes. Mol Cell Biol. 1995 Dec;15(12):710616.

28 Boender AJ, de Jong JW, Boekhoudt L, Luijendijk MC, van der Plasse G, Adan RA. Combined use of the canine adenovirus- 2 and DREADD-technology to activate specific neural pathways in vivo. PLoS One. 2014 Apr; 9(4):e95392.

29 Aponte Y, Atasoy D, Sternson SM: AGRP neurons are sufficient to orchestrate feeding behavior rapidly and without training. Nat Neurosci. 2011;14:351-354.

30 Robberecht P, Gourlet P, De Neef P, Woussen-Colle MC, Vandermeers-Piret MC, Vandermeers A, et al. Structural requirements for the occupancy of pituitary adenylate-cyclase-activating-peptide (PACAP) receptors and adenylate cyclase activation in human neuroblastoma NB-OK-1 cell membranes. Discovery of PACAP(6-38) as a potent antagonist. Eur J Biochem. 1992 Jul; 207(1):239-46.

31 Liu DM, Cuevas J, Adams DJ. VIP and PACAP potentiation of nicotinic ACh-evoked currents in rat parasympathetic neurons is mediated by G-protein activation. Eur J Neurosci. 2000 Jul;12(7):2243-51.

32 Zhou Y, Castonguay P, Sidhom EH, Clark AR, Dvela-Levitt M, Kim S, et al. A small- molecule inhibitor of TRPC5 ion channels suppresses progressive kidney disease in animal models. Science. 2017 Dec;358(6368): 1332-6.

33 Conde K, Meza C, Kelly MJ, Sinchak K, Wagner EJ. Estradiol rapidly attenuates ORL-1 receptor-mediated inhibition of proopiomelanocortin neurons via Gq-coupled, membrane-initiated signaling. Neuroendocrinology. 2016;103(6):787-805.

34 Brager DH, Johnston D. Plasticity of intrinsic excitability during long-term depression is mediated through mGluR-dependent changes in $\mathrm{I}(\mathrm{h})$ in hippocampal CA1 pyramidal neurons. J Neurosci. 2007 Dec;27(51):1392637.

35 Wang W, Le AA, Hou B, Lauterborn JC, Cox CD, Levin ER, et al. Memory-related synaptic plasticity is sexually dimorphic in rodent hippocampus. J Neurosci. 2018 Sep;38(37):793551.

36 Krashes MJ, Shah BP, Madara JC, Olson DP, Strochlic DE, Garfield AS, et al. An excitatory paraventricular nucleus to AgRP neuron circuit that drives hunger. Nature. 2014 Mar; 507(7491):238-42.

37 Qiu J, Bosch MA, Meza C, Navarro UV, Nestor CC, Wagner EJ, et al. Estradiol protects proopiomelanocortin neurons against insulin resistance. Endocrinology. 2018 Feb; 159(2):647-64.

38 Fabelo C, Hernandez J, Chang R. S. S, Alicea N, Tian S, Conde K, Wagner EJ: endocannabinoid signaling at hypothalamic steroidogenic factor-1/proopiomelanocortin synapses is sex- and diet-sensitive. Front Mol Neurosci. 2018;11:214.

39 Hernandez J, Fabelo C, Perez L, Moore C, Chang R, Wagner EJ. Nociceptin/orphanin FQ modulates energy homeostasis through inhibition of neurotransmission at VMN SF-1/ARC POMC synapses in a sex- and dietdependent manner. Biol Sex Differ. 2019 Feb; 10(1):9.

40 Merriam LA, Roman CW, Baran CN, Girard BM, May V, Parsons RL. Pretreatment with nonselective cationic channel inhibitors blunts the PACAP-induced increase in guinea pig cardiac neuron excitability. J Mol Neurosci. 2012 Nov;48(3):721-9.

41 Hill JW, Williams KW, Ye C, Luo J, Balthasar $\mathrm{N}$, Coppari R, et al. Acute effects of leptin require PI3K signaling in hypothalamic proopiomelanocortin neurons in mice. J Clin Invest. 2008 May;118(5):1796-805.

42 Gao Y, Yao T, Deng Z, Sohn JW, Sun J, Huang $\mathrm{Y}$, et al. TrpC5 mediates acute leptin and serotonin effects via Pomc neurons. Cell Rep. 2017 Jan;18(3):583-92.

43 Plum L, Ma X, Hampel B, Balthasar N, Coppari R, Münzberg H, et al. Enhanced PIP3 signaling in POMC neurons causes KATP channel activation and leads to diet-sensitive obesity. J Clin Invest. 2006 Jul;116(7): 1886-901.

44 Claret M, Smith MA, Batterham RL, Selman C, Choudhury AI, Fryer LG, et al. AMPK is essential for energy homeostasis regulation and glucose sensing by POMC and AgRP neurons. J Clin Invest. 2007 Aug;117(8): 2325-36.

45 Qiu J, Zhang C, Borgquist A, Nestor CC, Smith AW, Bosch MA, et al. Insulin excites anorexigenic proopiomelanocortin neurons via activation of canonical transient receptor potential channels. Cell Metab. 2014 Apr; 19(4):682-93.

46 Dodd GT, Decherf S, Loh K, Simonds SE, Wiede F, Balland E, et al. Leptin and insulin act on POMC neurons to promote the browning of white fat. Cell. 2015 Jan;160(1-2):88104.

47 Dodd GT, Michael NJ, Lee-Young RS, Mangiafico SP, Pryor JT, Munder AC, et al. Insulin regulates $\mathrm{POMC}$ neuronal plasticity to control glucose metabolism. eLife. 2018 Sep; 7:e38704.

48 He Z, Gao Y, Lieu L, Afrin S, Guo H, Williams $\mathrm{KW}$. Acute effects of zinc and insulin on arcuate anorexigenic proopiomelanocortin neurons. Br J Pharmacol. 2019 Mar;176(5):72536.

49 Iemolo A, Seiglie M, Blasio A, Cottone P, Sabino V. Pituitary adenylate cyclase-activating polypeptide (PACAP) in the central nucleus of the amygdala induces anxiety via melanocortin receptors. Psychopharmacology (Berl). 2016 Sep;233(17):3269-77.

50 Mela V, Vargas A, Meza C, Kachani M, Wagner EJ. Modulatory influences of estradiol and other anorexigenic hormones on metabotropic, Gi/o-coupled receptor function in the hypothalamic control of energy homeostasis. J Steroid Biochem Mol Biol. 2016 Jun;160:1526.

51 Klöckener T, Hess S, Belgardt BF, Paeger L, Verhagen LAW, Husch A, et al. High-fat feeding promotes obesity via insulin receptor/ PI3K-dependent inhibition of SF-1 VMH neurons. Nat Neurosci. 2011;14:911-918.

52 Chee MJ, Price CJ, Statnick MA, Colmers WF. Nociceptin/orphanin FQ suppresses the excitability of neurons in the ventromedial nucleus of the hypothalamus. J Physiol. $2011 \mathrm{Jul}$; 589(Pt 13):3103-14.

53 Shioda S, Ohtaki H, Nakamachi T, Dohi K, Watanabe J, Nakajo S, et al. Pleiotropic functions of PACAP in the CNS: neuroprotection and neurodevelopment. Ann N Y Acad Sci. $2006 \mathrm{Jul} ; 1070(1): 550-60$.

54 Macdonald DS, Weerapura M, Beazely MA, Martin L, Czerwinski W, Roder JC, et al. Modulation of NMDA receptors by pituitary adenylate cyclase activating peptide in CA1 neurons requires $\mathrm{G}$ a q, protein kinase $\mathrm{C}$, and activation of Src. J Neurosci. 2005 Dec;25(49): 11374-84.

55 Castorina A, Scuderi S, D'Amico AG, Drago F, D'Agata V. PACAP and VIP increase the expression of myelin-related proteins in rat schwannoma cells: involvement of PAC1/ VPAC2 receptor-mediated activation of PI3K/Akt signaling pathways. Exp Cell Res. 2014 Mar;322(1):108-21. 
56 Gupte RP, Kadunganattil S, Shepherd AJ, Merrill R, Planer W, Bruchas MR, et al. Convergent phosphomodulation of the major neuronal dendritic potassium channel Kv4.2 by pituitary adenylate cyclase-activating polypeptide. Neuropharmacology. 2016 Feb;101: 291-308.

57 Spence JP, Reiter JL, Qiu B, Gu H, Garcia DK, Zhang L, et al. Estrogen-Dependent Upregulation of Adcyap1r1 Expression in Nucleus Accumbens Is Associated With Genetic Predisposition of Sex-Specific QTL for Alcohol Consumption on Rat Chromosome 4. Front Genet. 2018 Dec;9:513.

58 Moore JP Jr, Burger LL, Dalkin AC, Winters SJ. Pituitary adenylate cyclase activating polypeptide messenger RNA in the paraventricular nucleus and anterior pituitary during the rat estrous cycle. Biol Reprod. 2005 Sep;73(3): 491-9.

59 Wade GN, Gray JM. Gonadal effects on food intake and adiposity: a metabolic hypothesis. Physiol Behav. 1979 Mar;22(3):583-93.

60 Johnson WG, Corrigan SA, Lemmon CR, Bergeron $\mathrm{KB}$, Crusco AH. Energy regulation over the menstrual cycle. Physiol Behav. 1994 Sep;56(3):523-7.

61 Qiu J, Xue C, Bosch MA, Murphy JG, Fan W, Rønnekleiv OK, et al. Serotonin 5-hydroxytryptamine $2 \mathrm{C}$ receptor signaling in hypothalamic proopiomelanocortin neurons: role in energy homeostasis in females. Mol Pharmacol. 2007 Oct; 72(4):885-96.

62 Kelly MJ, Lagrange AH, Wagner EJ, Rønnekleiv OK. Rapid effects of estrogen to modulate $\mathrm{G}$ protein-coupled receptors via activation of protein kinase $\mathrm{A}$ and protein kinase $\mathrm{C}$ pathways. Steroids. 1999 Jan-Feb;64(1-2):6475.
63 Qiu J, Bosch MA, Tobias SC, Krust A, Graham SM, Murphy SJ, et al. A G-protein-coupled estrogen receptor is involved in hypothalamic control of energy homeostasis. J Neurosci. 2006 May;26(21):5649-55.

64 Washburn N, Borgquist A, Wang K, Jeffery GS, Kelly MJ, Wagner EJ. Receptor subtypes and signal transduction mechanisms contributing to the estrogenic attenuation of cannabinoid-induced changes in energy homeostasis. Neuroendocrinology. 2013;97(2):160-75.

65 Borgquist A, Meza C, Wagner EJ. Role of neuronal nitric oxide synthase in the estrogenic attenuation of cannabinoid-induced changes in energy homeostasis. J Neurophysiol. 2015 Feb;113(3):904-14.

66 Thorens B. Brain glucose sensing and neural regulation of insulin and glucagon secretion. Diabetes Obes Metab. 2011 Oct;13 Suppl 1: 82-8.

67 Musatov S, Chen W, Pfaff DW, Mobbs CV Yang XJ, Clegg DJ, et al. Silencing of estrogen receptor $\alpha$ in the ventromedial nucleus of hypothalamus leads to metabolic syndrome. Proc Natl Acad Sci USA. 2007 Feb;104(7): 2501-6.

68 Cagnacci A, Volpe A, Paoletti AM, Melis GB. Regulation of the 24-hour rhythm of body temperature in menstrual cycles with spontaneous and gonadotropin-induced ovulation. Fertil Steril. 1997 Sep;68(3):421-5.

69 Stephenson LA, Kolka MA. Esophageal temperature threshold for sweating decreases before ovulation in premenopausal women. J Appl Physiol (1985). 1999 Jan;86(1):22-8.

70 Roepke TA, Bosch MA, Rick EA, Lee B, Wagner EJ, Seidlova-Wuttke D, et al. Contribution of a membrane estrogen receptor to the estrogenic regulation of body temperature and energy homeostasis. Endocrinology. 2010 Oct;151(10):4926-37.
71 Minokoshi Y, Alquier T, Furukawa N, Kim YB, Lee A, Xue B, et al. AMP-kinase regulates food intake by responding to hormonal and nutrient signals in the hypothalamus. Nature. 2004 Apr;428(6982):569-74.

72 Borgquist A, Meza C, Wagner EJ. The role of AMP-activated protein kinase in the androgenic potentiation of cannabinoid-induced changes in energy homeostasis. Am J Physiol Endocrinol Metab. 2015 Mar;308(6):E48295.

73 Conde K, Fabelo C, Krause WC, Propst R, Goethel J, Fischer D, et al. Testosterone rapidly augments retrograde endocannabinoid signaling in proopiomelanocortin neurons to suppress glutamatergic input from steroidogenic factor 1 neurons via upregulation of diacylglycerol lipase- $\alpha$. Neuroendocrinology. 2017;105(4):341-56.

74 Hurley MM, Robble MR, Callan G, Choi S, Wheeler RA. Pituitary adenylate cyclase-activating polypeptide (PACAP) acts in the nucleus accumbens to reduce hedonic drive. Int J Obes. 2019 Apr;43(4):928-32.

$75 \mathrm{Vu}$ JP, Goyal D, Luong L, Oh S, Sandhu R, Norris J, et al. PACAP intraperitoneal treatment suppresses appetite and food intake via $\mathrm{PAC} 1$ receptor in mice by inhibiting ghrelin and increasing GLP-1 and leptin. Am J Physiol Gastrointest Liver Physiol. 2015 Nov; 309(10):G816-25.

76 Spierling SR, Kreisler AD, Williams CA, Fang SY, Pucci SN, Kines KT, et al. Intermittent, extended access to preferred food leads to escalated food reinforcement and cyclic wholebody metabolism in rats: sex differences and individual vulnerability. Physiol Behav. 2018 Aug;192:3-16. 